Universidad de Lima

Escuela de Posgrado

Maestría en Tributación y Política Fiscal

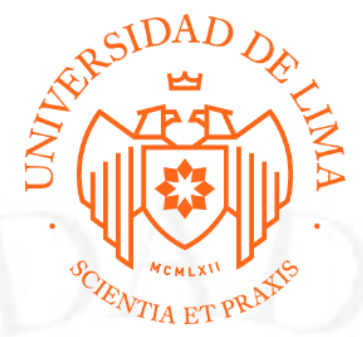

\title{
TERRITORIOS DE BAJA O NULA IMPOSICIÓN: \\ MEDIDAS NECESARIAS EN EL IMPUESTO A LA RENTA EN EL PERÚ
}

Trabajo de investigación para optar el Grado Académico de Maestro en Tributación y Política Fiscal

\section{Carlos Aurelio Zapata Salsavilca Código 19863248}

\section{Asesor}

Fernando Núñez Ciallella

$$
\begin{aligned}
& \text { Lima - Perú } \\
& \text { Julio de } 2019
\end{aligned}
$$




\section{TERRITORIOS DE BAJA O NULA IMPOSICIÓN: MEDIDAS NECESARIAS EN EL IMPUESTO A LA RENTA EN EL PERÚ}

\section{TAX HAVENS OR LOW-TAX \\ JURISDICTIONS: NECESSARY MEASURES \\ IN THE INCOME TAX IN PERÚ}




\section{TABLA DE CONTENIDO}

INTRODUCCIÓN ..............................................................................................1

CAPÍTULO I: MARCO CONCEPTUAL..........................................................3

1.1 Paraíso Fiscal, Centro Offshore, Territorio de Baja o Nula Imposición 3

1.1.1 Definición 3

1.1.2 Para que Sirven los Paraísos Fiscales. 4

1.1.3 Evasión, Elusión, Fraude de Ley Tributaria y Planificación Fiscal9

1.1.4 Ventajas y Desventajas de los Paraísos Fiscales .13

1.1.5 Casos Prácticos de Traslado de Beneficios a Países o Territorios de Baja o Nula Imposición. .16

1.2 OCDE: Posiciones y Acuerdos Realizados con los Paraísos Fiscales 18

1.3 BEPS: La Erosión de las Bases Tributarias y el Desvío de Utilidades 19

1.3.1 Principios de la Imposición de las actividades Transfronterizas y

Erosión de las Base Imponibles - OCDE .22

CAPÍTULO II: MARCO LEGAL PERUANO .29

2 Territorio de Baja o Nula Imposición en la LIR ....................................29

2.1.1 Países o Territorios de Baja o Nula Imposición .29

2.1.2 Calificación de Países o Territorios no cooperantes o de baja o nula imposición 30

2.1.3 Calificación de Regímen Fiscal Preferencial .33

2.1.4 Nuevos Factores en la LIR para calificar Países o territorios no cooperantes o de baja o nula imposición y Régimen Fiscal Preferencial .36

2.2 Acuerdo de Intercambio de Información .45

2.2.1 Acuerdos de Intercambio de Información, factor para calificar un país o territorio no cooperante de baja o nula imposición y régimen fiscal preferencial.....45 
2.2.2 Países que suscribieron Convenios de Doble Imposición con el Perú....46

2.2.3 Acuerdos de Intercambio de Información suscritos con Países con los cuales no tenemos Convenios de Doble Imposición .48

2.2.4 Acuerdos de Intercambio de Información con Organismos Internacionales 52

2.3 Medidas Antielusivas contra Países o Territorios no cooperantes o de baja o nula imposición y Regímenes Fiscales preferenciales .56

\section{CAPÍTULO III: MEDIDAS ADICIONALES QUE SE DEBEN} IMPLEMENTAR EN EL IMPUESTO A LA RENTA. .60

3.1 Incorporar en la Ley y el Reglamento del Impuesto a la Renta las siguientes modificaciones .60

3.2 Suscribir más Acuerdos de Intercambio de Información .66

3.3 Los Regímenes Fiscales Preferenciales deben ser publicados en forma explicita en las normas peruanas .68

3.4 Modificación en la Tasa de Retención del Impuesto a la Renta: Intereses 70

3.5 CONCLUSIONES Y RECOMENDACIONES 


\section{RESUMEN}

En esta investigación, se analizarán ciertos aspectos de las medidas antielusivas que hay en el Perú para protegerse de las operaciones realizadas por los contribuyentes en los países o territorios de Baja o Nula Imposición, para esto se desarrollan los temas en tres capítulos.

En el primer capítulo se ve el marco conceptual de estas jurisdicciones; el segundo capítulo trata sobre el marco legal peruano; y en el tercer capítulo se analizan las medidas adicionales que se pueden implementar para que las operaciones realizadas en los Países o Territorios de Baja o Nula Imposición y Regímenes Fiscales Preferenciales puedan ser gravadas en la forma más óptima posible sin que perjudique al contribuyente y/o al Tesoro Público.

Palabras clave: Territorio de Baja o Nula Imposición, Erosión de las Bases Imponibles y Traslado de Beneficios, Transparencia, Intercambio de Información, Medidas Defensivas, Ley del impuesto a la Renta. 


\begin{abstract}
In this investigation, certain aspects of the defensive measures in Peru to protect themselves from the operations carried out by taxpayers in Tax-Havens or low-tax territories will be analyzed, for this the topics are developed in three chapters.

The conceptual framework of these jurisdictions is seen in the first chapter; the second chapter deals with the Peruvian legal framework; and in the third chapter, we analyze the additional measures that can be implemented so that the operations carried out in the countries or territories of Low Taxation and Preferential Tax Regimes can be taxed as optimally as possible without harming the taxpayer or harming the Public Treasure.
\end{abstract}

Keywords: Tax Havens or Low-Tax Jurisdictions, Base Erosion and Profit Shifting Project, Transparency, Exchange of Information, Defensive Measures, Income Tax Law. 


\section{INTRODUCCIÓN}

La erosión de las Bases Imponibles y el Traslado de Beneficios realizados a través de Países o Territorios de Baja o Nula Imposición y Regímenes fiscales preferenciales en los principales países del mundo originó que la OCDE y el G20 promovieran la creación de un foro Multilateral y el Marco Inclusivo sobre BEPS (Base Erosion and Profit shifting) que cuenta con la adherencia de decenas de países, y pretende estandarizar las normas de fiscalidad internacional.

Los vacíos en las normas y la falta de armonía en la legislación de diferentes países permiten la evasión, elusión y la economía de opción de las empresas multinacionales a través de los países o territorios de Baja o Nula Imposición para reducir su carga tributaria.

La OCDE en su informe "Harmful Tax Competition - An emerging Global Issue" publicado en el año 1998, consignó sus primeras recomendaciones para combatir a dichas jurisdicciones.

Los paraísos fiscales existen desde más de un siglo, su denominación fue cambiando con el tiempo a Países o Territorios de Baja o Nula imposición; luego, a raíz de la implementación de las medidas BEPS, cambió la denominación de estas jurisdicciones a países o territorios no cooperantes o de baja o nula imposición y Regímenes Fiscales preferenciales, siendo la OCDE la que establece cuales son los criterios a considerar para calificarlos como tales.

En el Perú, las medidas antielusivas de fiscalidad internacional fueron incluyéndose en la Ley del Impuesto a la Renta desde el año 2001 y durante todos estos años se ha ido modificando y perfeccionando las mismas. Las últimas modificaciones publicadas en los años 2013, 2016 y 2018 permitieron actualizar las normas a los estándares internacionales sugeridos por la OCDE y las medidas BEPS

La OCDE ha exigido la suscripción de acuerdos de Intercambio de Información y Transparencia, y, asimismo, la implementación de medidas BEPS para que los países o territorios de baja o nula imposición no sean clasificados como países no cooperantes, lo mismo sucede con los Regímenes Fiscales preferenciales. 
Las modificatorias de la Ley del Impuesto a la Renta y su Reglamento en el 2018, en sus exposiciones de motivos, resaltan la necesidad de actualizar las normas peruanas para que las Medidas BEPS puedan estar mejor implementadas y evitar la elusión a través de los Países o Territorios no cooperantes de Baja o Nula Imposición y Regímenes fiscales preferenciales.

El Perú tiene muy pocos Convenios de Doble Imposición y Acuerdos de Intercambio de información para evitar la doble imposición y combatir la erosión de las Bases Imponibles y Traslado de beneficios a los países o territorios de baja o nula imposición y regímenes fiscales preferenciales

El Objetivo de este trabajo es hacer un análisis de ciertos aspectos de las medidas antielusivas que hay en el Perú para protegerse de las operaciones realizadas por los contribuyentes en los países o territorios de Baja o Nula Imposición, para esto se desarrollan los temas en tres capítulos.

En el primer capítulo se ve el marco conceptual de estas jurisdicciones; el segundo capítulo trata sobre el marco legal peruano; y en el tercer capítulo se analizan las medidas adicionales que se pueden implementar para que las operaciones realizadas en los Países o Territorios de Baja o Nula Imposición y Regímenes Fiscales Preferenciales puedan ser gravadas en la forma más óptima posible sin que perjudique al contribuyente y/o al Tesoro Público. 


\section{CAPÍTULO I: MARCO CONCEPTUAL}

\subsection{Paraíso Fiscal, Centro Offshore, Territorio de Baja o Nula Imposición}

\subsubsection{Definición}

Los paraísos fiscales también son llamados centros financieros "offshore", centros financieros extraterritoriales o incluso "centros financieros internacionales".

El término original es "Tax Haven" que significa refugio fiscal, el cual fue traducido erróneamente al español como "paraíso fiscal".

Muchos Autores e investigadores hacen referencia a que no existe una definición uniforme de paraíso fiscal, cada país tiene sus propias valoraciones para definirlo.

Chávez Chávez (2014) en su artículo "Los paraisos fiscales y su impacto global en América Latina (México) publicado en la Revista Cimexus resalta que no existe una definición uniforme y propone la siguiente definicion:

No existe una definición oficial o estandarizada que explique exactamente lo que debe entenderse por paraíso fiscal. Sólo podré recurrir a la definición que creo más ajustada.

Un "Paraíso Fiscal" puede ser un país, un territorio, una determinada región o también una actividad económica que se busca privilegiar frente al resto, con la finalidad de captar fuertes inversiones, constituir sociedades, acoger personas físicas con grandes capitales, etc. Dicho de otro modo, los paraísos fiscales son aquellos sitios que atraen a los inversores extranjeros por el trato fiscal favorable que reciben. Conforme se puede apreciar, el término "paraíso fiscal" admite múltiples posibilidades, por ello es recomendable utilizar el término "países o zonas de baja tributación”. (pág. 15)

Picón Gonzales (2016) en su tesis los "Paraisos Fiscales como Herramienta de Planificación Tributaria" manifiesta que "es importante señalar que no existe una 
definición única de Paraíso Fiscal, la mayor parte de los autores solo se ponen de acuerdo en la concurrencia de una serie de características en los mencionados Paraísos, a las que luego aludiremos, pero no hay una definición concreta de Paraíso Fiscal”. (pág. 56)

Asimismo, Picón Gonzales (2016) indica que él entiende como Paraíso Fiscal lo siguiente:

Es así que desde un punto de vista técnico resulta difícil determinar objetivamente cuando un régimen fiscal puede ser calificado de paraíso fiscal, ya que podemos entender a grandes rasgos por "paraíso fiscal" al territorio o Estado que se caracteriza por una escasa o nula tributación a que someten a determinada clase de transacciones, ventas a determinadas personas o entidades que allí encuentran su cobertura o amparo. (pág. 56)

Entonces, si bien el paraíso fiscal no tiene una definición uniforme a nivel mundial, los diferentes conceptos señalan lo siguiente:

Un paraíso fiscal es un país, estado o territorio que busca privilegiar a personas jurídicas o naturales no residentes en relación a los residentes, con el objeto de captar inversiones, constituir sociedades y acoger a personas con grandes capitales ofreciendo niveles de tributación bajos o nulos, donde los operadores económicos poseen el anonimato que provee el secreto bancario, mercantil y profesional.

\subsubsection{Para qué sirven los Paraísos Fiscales}

En el último siglo, la globalización de la economía facilitó la movilidad de los capitales e inversiones en el mundo.

Los mercados cada día son más abiertos y con menos restricciones para el flujo de los bienes y servicios, por ese motivo hay países y territorios que con el objeto de atraer inversiones y capitales otorgan diversas ventajas y facilidades a las empresas y personan físicas para que inviertan en ellos. Una de esas ventajas es la nula o baja imposición, así como el secreto bancario y protección de datos personales.

La mayoría de autores, investigadores y organismos internacionales relacionan a los paraísos fiscales con actividades de elusión y evasión de impuestos; sin embargo, hay 
algunos que señalan que estos territorios sirven para realizar actividades válidas de Planeamiento Tributario Internacional.

OXFAM (2016) señala que los paraísos fiscales han permitido que las empresas incrementen el traslado de beneficios a dichas jurisdicciones, las cuales quedan sin tributar:

Durante las últimas décadas, las contribuciones fiscales de las grandes empresas se han ido reduciendo a causa de esta competencia agresiva en la fiscalidad empresarial generalizada. En los últimos treinta años, los beneficios netos registrados por las empresas más grandes del mundo se multiplicaron por más de tres en términos reales, pasando de 2 billones de dólares en 1980 a 7,2 billones de dólares en 2013. La existencia de paraísos fiscales ha facilitado que éste incremento en los beneficios empresariales no se haya visto acompañado de una mayor contribución fiscal. (pág. 3)

Marulanda, Hugo y Heredia, Liliana (2016) señalan que los Organismos Internacionales afirman que la erosión de la base imponible y disminución de la recaudación fiscal de los países se deben al traslado de los beneficios empresariales a los paraísos fiscales y regímenes fiscales preferenciales a traves de planeamientos fiscales agresivos. Si bien se han tomado medidas para combatirlos, existen muchas dificultades para lograrlo:

Organismos internacionales como la OCDE, la UE, el G7/G8 y el G20 han adelantado diversos estudios y trabajos para combatir y evitar la proliferación de vehículos fiscales opacos o fraudulentos como las practicas fiscales perniciosas, los regímenes fiscales preferenciales y, en especial, los paraísos fiscales, todo ello con el ánimo de prevenir la erosión de la base imponible y la disminución de la recaudación fiscal que se ocasiona por el traslado de los beneficios empresariales a jurisdicciones de baja o nula tributación. Sin embargo, estos esfuerzos se han quedado bajo la línea de la formalidad, puesto que en la línea de la materialidad persisten la planificación fiscal agresiva, el secreto bancario y la opacidad en el intercambio de información financiera y tributaria. (pág. 5)

Existen autores que piensan que es valido el uso de los paraísos fiscales por las empresas y personas naturales para disminuir su carga tributaria. 
Alva Matteucci (2001) en su articulo "Los Paraisos fiscales" cita a Fernando Serrano Anton señalando que es legítimo el uso de los mismos:

De acuerdo a lo manifestado por Fernando Serrano '...la mayoría de los autores identifican la utilización de los paraísos fiscales con actividades de evasión y fraude fiscal. Otros, en cambio, pensamos que tales territorios se relacionan más con actividades legítimas de planificación fiscal internacional. (2001)

Los autores Falcón y Tella, y Pulido (2010) señalan en su libro Derecho Fiscal Internacional lo siguiente:

Con la expresión paraíso fiscal, o «refugio fiscal» (tax haven), usualmente se designan aquellas zonas en las que existe una presión tributaria, directa o indirecta, nula (no tax haven) o muy escasa, y que al mismo tiempo presentan características de desarrollo, estabilidad política y social, e inexistencia de control de cambios (y por tanto posibilidad de transferir fondos al exterior libremente), que las hacen susceptibles de ser utilizadas en las estrategias de planificación fiscal. (pág. 261)

Sin embargo, usualmente se tiene como concepto que un paraíso fiscal es un país, estado o territorio con niveles de tributación bajos o nulos, donde los operadores económicos gozan del anonimato que proporcionan el secreto bancario, mercantil y profesional, de esta manera erosionan la Base Imponible del Impuesto a la renta en muchos países. Los Paraísos Fiscales tienen las siguientes caracteristicas:

- Fiscalidad Nula o Reducida

- Normativa Financiera y mercantil Flexible: Las empresas offshore se pueden constituir facilmente consignando el nombre de los representantes pero no el nombre de los verdaderos dueños, lo mismo sucede en las cuentas bancarias

- No existe intercambio de informacion

- Residentes y No Residentes: Los no residentes que constituyen empresas o negocios estan exentas de impuestos en contraposicion a los residentes, asimismo no realizan operaciones en dichos territorios

- No hay actividades sustanciales en la jurisdicción. 
Estas caracteristicas o factores son señaladas por diversos autores o investigadores como Jiménez Macías (2017) en su tesis doctoral:

Para definir qué es un CFO, TJN acude a los trabajos realizados por el Foro de Estabilidad Financiera (FEF) en los que concluyen que los centros financieros offshore se caracterizan por ser jurisdicciones con unas características regulatorias específicas. Dice que los centros financieros offshore no son fáciles de definir, pero pueden ser caracterizados como jurisdicciones que atraen un alto nivel de actividad de no residentes. Tradicionalmente el término ha implicado algunas o todas de las siguientes características:

- Baja o nula tributación.

- Falta de retenciones.

- Sencillez en la constitución de sociedades.

- Sistemas de supervisión poco estrictos o laxos.

- Facilidad en el uso de vehículos societarios como los Trusts.

- No existe obligación para las instituciones financieras de presencia física para operar.

- Alto nivel de confidencialidad soportado por su régimen legal.

- Los anteriores incentivos no se ofrecen a residentes (págs. 36-37)

Asimismo Marieges, Suñer, Vallès y Vidal (2012) en su tesis de la Universidad Pompeu Fabra - Barcelona señalan lo siguiente:

Las diferentes características que pueden presentar los paraísos fiscales son las siguientes:

- Fiscalidad nula o reducida

- Normativa financiera flexible

- Sistema regulatorio dual

- No intercambio de información

Además de las características anteriores, que podemos considerar como las más representativas, también cabe destacar que en algunos de estos países los datos personales de propietarios y accionistas de empresas no figuran en los registros públicos, o bien se permite el empleo de representantes formales (llamados nominees). (págs. 6-7) 
En 1998 la OECD estableció una serie de factores para identificar los paraísos fiscales, los cuatro considerados claves son los siguientes:

- No hay Impuesto Nominal o es muy bajo;

- Ausencia de intercambio de información entre jurisdicciones;

- Ausencia de Transparencia;

- No hay actividades sustanciales en la jurisdicción.

En el documento de la OCDE (2009) llamado "Countering Offshore Tax Evasion Some Questions and Answers" está plasmado lo siguiente:

In 1998 the OECD set out a number of factors for identifying tax havens. The four key factors were:

1) No or nominal tax on the relevant income;

2) Lack of effective exchange of information;

3) Lack of transparency;

4) No substantial activities. (pág. 11)

La OCDE señala que no basta que solo haya baja o nula tributación sino tiene que estar alguno de los factores señalados en el párrafo anterior.

La OCDE, para determinar si una jurisdicción es cooperante, señala el cuarto factor "No hay actividades sustanciales" no iba a ser considerado, por lo tanto para no ser incluido como paraíso fiscal no cooperante, se pidió a las jurisdicciones que cumplían con los criterios estipulados que se comprometieran a implementar los principios de transparencia e intercambio de información con fines tributarios.

En el libro Derecho Fiscal Internacional resaltan este hecho:

La OCDE, en un informe sobre Competencia fiscal perjudicial: una cuestión global emergente de 1998, definió los paraísos fiscales como aquellos territorios en que, por un lado, no existe tributación o los tipos efectivamente aplicados son muy bajos, y por otro lado, concurre alguna de las tres notas siguientes:

- Falta de intercambio de información efectiva.

- Falta de transparencia, en el sentido de que no se conozca la aplicación práctica que se hace de las disposiciones legales, administrativas o legislativas. 
- Falta de actividad económica sustancial (criterio que fue eliminado en 2001) (Falcon y Tella \& Pulido Guerra, 2010, pág. 261)

Por lo expuesto, la utilización de los Territorios de Baja o Nula imposición ocasionan la erosión de las bases imponibles lo cual es una amenaza para los ingresos tributarios de los Estados, poniendo en riesgo la soberanía y la equidad fiscal de los países.

Esa erosión puede ser realizada por los operadores económicos a través de la evasíon, elusión o Planificación Fiscal, estas dos últimas son actividades lícitas.

\subsubsection{Evasión, Elusión, Fraude de Ley Tributaria y Planificación Fiscal}

Antes de analizar las ventajas y desventajas de los paraísos fiscales debemos tener claro una serie de conceptos.

\section{Evasión}

La Evasión son las acciones utilizadas por los contribuyentes para evitar el pago de impuestos violando para ello la ley.

En la evasión se produce el hecho imponible y nace la obligación tributaria, pero dicha realización o el verdadero monto de la operación se oculta a la Administración Tributaria, por lo tanto es ilegal.

Al respecto (Bedoya Martinez \& Rua, 2016) efectúan la siguiente cita:

"por otro lado la evasión fiscal, es la conducta ilícita por el ocultamiento de todo o parte del hecho imponible, que realiza el sujeto pasivo, para evitar el pago de la deuda tributaria, estando obligado por la ley.” (Ochoa León, 2014)

\section{Elusión}

La elusión de impuestos es la conducta de los contribuyentes que buscan evitar el pago de impuesto utilizando para ello estrategias permitidas por la misma ley o por los vacíos de esta. 
La figura jurídica de la Elusión permite al contribuyente evitar el hecho de la hipótesis de incidencia tributaria, eludiendo que se concrete el hecho imponible y en consecuencia no nazca la obligación tributaria, todo ello con la finalidad de no pagar los tributos procurando para ello “forzar” alguna figura jurídica establecida en las leyes.

Según García Novoa (2008) la elusión es un evitamiento del hecho imponible no realizando el hecho imponible o realizando otro menos gravado en condiciones abusivas, pero que es diferente a la evasión, esta última implica la violación directa de la norma (pág. 328)

El IPDT (2019) señala lo siguiente:

La elusión es un comportamiento consistente en evitar el presupuesto de hecho de la obligación tributaria, o en disminuir la carga tributaria, a través de un medio jurídicamente anómalo, sin violar directamente el mandato de la regla jurídica, pero si los valores y principios del sistema tributario (pág. 2)

Se debe descartar que la elusión comprenda actos en simulación absoluta y relativa, pues ellos tienen como característica esencial la falsedad, al implicar hechos que se ocultan o disfrazan aparentado una realidad que no es tal. Por tanto, en esos casos se ha producido un hecho imponible -que es disimulado y no evitado-, el mismo que pretende ser ocultado con un negocio que no existe (simulación absoluta) o con un negocio aparente o que cubre a otro (simulación relativa), tipos legales regulados en los artículos 190 y 191 de nuestro Código Civil. Para estos supuestos, el legislador ha otorgado facultades distintas a la CAG, establecidas en el primer y último párrafos de la Norma XVI (pág. 3)

La elusión no es estrictamente ilegal, puesto que no se está violando ninguna ley, sino que es un aprovechamiento a través de una interpretación de una ley ambigua o con vacíos, muchas veces con interpretaciones "forzadas".

\section{Forma de Elusión: Fraude de Ley Tributaria}

En el fraude de ley existe una norma de cobertura que es usada en forma artificiosa con la finalidad que la norma que debió usarse no se aplique, motivo por el cual nos encontramos ante una norma defraudada. 
Picón Gonzales (2016), en sus tesis de doctorado, manifiesta lo siguiente:

Podemos apreciar que en la configuración del fraude a la ley existe una norma que es utilizada como soporte del acto artificioso, calificada como norma de cobertura y cuya naturaleza puede oscilar entre el campo civil, laboral o comercial; y una norma cuya aplicación se desactiva pese a que de la causa y finalidad económica del acto realizado se desprenda que dicha norma es la que debió aplicarse, razón por la cual nos encontraríamos ante una norma defraudada. (pág. 28)

Entonces, tenemos que respecto al Fraude de Ley Tributaria los contribuyentes realizan actos para evitar el pago de impuestos de la siguiente manera:

A través de actos jurídicos civil, comercial o laboralmente anómalos, se busca evitar la aplicación de una norma tributaria, pretendiendo caracterizar dicho acto como uno sometido a otra norma tributaria - normalmente menos gravosa que la que en rigor le corresponde - o como uno no sometido a norma tributaria alguna (Bravo Cucci, 2006, pág. 146)

Picón Gonzales (2016) señala que el Fraude de Ley Tributaria es una forma de elusión fiscal:

Una de las formas de eludir la aplicación de una norma tributaria es a través de la realización de negocios anómalos en fraude a la Ley Tributaria. Por lo tanto, el fraude a la ley tributaria es una forma de elusión fiscal. Por ello, se mencionaba en las líneas correspondientes a la elusión fiscal que ésta contenía una gama de posibilidades mediante las cuales concretarse, entre ellas la figura del fraude a la ley. (Picón Gonzales, 2016)

Bravo Cucci (2016) señala que en España el Fraude a la ley tributaria no es una especie del Fraude de Ley; asimismo, señala que en el primero no se realiza el hecho imponible sino un hecho equivalente pero no regulado en la norma:

Es importante reconocer que un importante sector de la doctrina española cuestiona la figura del fraude a la ley tributaria, en tanto el ordenamiento jurídico tributario español -al igual que el peruano- proscribe la analogía en materia tributaria, negando asimismo que sea una especie de género "fraude de ley", dado que este último presupone una actuación contraria al ordenamiento jurídico, lo que no ocurriría en el fraude a la ley tributaria ya que no se realizaría el hecho 
imponible sino uno equivalente. En esa Tesis Falcon y Tella sostiene que en el fraude a la ley tributaria se elude la ley tributaria al no realizarse el hecho imponible, sino "un hecho equivalente", pero no regulado en la ley tributaria defraudada, con lo cual si se pretendiera gravar el hecho equivalente, se recurriría a la analogía (pág. 146)

El IPDT (2019) respecto al Fraude de Ley Tributaria tiene una posición distinta:

El Fraude de ley civil busca incumplir una norma imperativa (defraudada) obteniéndose el "resultado prohibido" mediante una figura jurídica amparada en otra norma (de cobertura); concepto que difiere del denominado fraude de ley tributario ya que éste forma parte de un derecho imperativo de segundo grado, lo que implica que, si no se realiza la conducta tipificada como hecho imponible, la obligación tributaria no se genera y, en consecuencia, no hay comportamiento prohibido burlado. Por ello, se requiere una norma antifraude que capture aquellos supuestos que se esquivaron. (pág. 3)

Como se ha indicado en la mayoría de los párrafos anteriores, en el fraude de ley Tributario existe una norma de cobertura que es usada en forma artificiosa con la finalidad que la norma que debió usarse no se aplique, motivo por el cual nos encontramos ante una norma defraudada, en la legislación tributaria debe estar tipificada en forma mas específica para evitar discusiones e incertidumbre sobre estos temas.

\section{Economía de Opción, Planificación Fiscal y Planificación tributaria}

La Economía de opción también es denominada Planificación Fiscal o Planificación Tributaria.

En la economía de Opción se busca a través de medios lícitos el ahorro de la carga físcal a través de realizar operaciones que no se encuentren dentro del ámbito de aplicación del Impuesto o que se tribute un menor impuesto.

$\mathrm{Al}$ respecto Lalanne (2006) en su artículo publicado en la revista del IPDT indica lo siguiente:

La economía de opción se hace precisamente aplicando correctamente la norma o valiéndose de los resquicios que el propio legislador, por desconocimiento o voluntad, ha establecido al momento de regular positivamente una determinada situación o negocio. (págs. 111-112) 
Los contribuyentes tienen libertad de realizar las operaciones de negocios que consideren convenientes, asimismo tienen derecho a decidir como obtener de manera lícita una reducción de la carga tributaria, sobre este punto tenemos que:

El derecho a la Planificación Fiscal lícita significa derecho a aprovechar las economías de opción que se deriven del ordenamiento tributario, incluso las implícitas, que son las que habrá que presumir cuando la ley no grave expresamente un supuesto que, hay que deducir, podría haber gravado. Aspecto que se verá amparado en el Principio de Reserva de Ley del Derecho Tributario y que como se apreció permite frenar la potestad tributaria estatal (Picón Gonzales, 2016, pág. 29)

En la Legislación Peruana recientemente se publicó con fecha 06/05/2019 en el diario El Peruano el Decreto Supremo No 145-2019-EF que en su artículo 2.- inciso i) define Economía de Opción:

A la acción de elegir y el resultado de elegir llevar a cabo actos que tributariamente son menos onerosos que otros posibles o disponibles en el ordenamiento jurídico y respecto de los cuales no se presentan ninguna de las circunstancias previstas en los literales a) y b) del tercer párrafo de la norma XVI del Título Preliminar del Código Tributario.

Asimismo, en el dispositivo referido en su artículo 2.- inciso h) define como Ahorro o Ventaja Tributaria lo siguiente:

A la reducción total o parcial de la deuda tributaria; a la reducción o eliminación de la base imponible; a posponer o diferir la obligación tributaria o deuda tributaria; a la obtención de saldos a favor, créditos, devoluciones o compensaciones, pérdidas tributarias o créditos por tributos; a la obtención de inmunidad tributaria, inafectación, no gravado, exoneración o beneficio tributario; a la sujeción a un régimen especial tributario; a cualquier situación que conlleve a que la persona o entidad deja de estar sujeto o reduzca o posponga su sujeción a tributos o el pago de tributos.

\subsubsection{Ventajas y Desventajas de los Paraísos Fiscales}

Las empresas multinacionales hacen uso de las diferentes ventajas tributarias que pueden obtener del uso de las normas tributarias de cada país, aprovechando sus vacíos legales y 
trasladando la mayoría de sus ganancias a Territorios de Baja o Nula Imposición, algunos lo hacen a través de la Planificación Fiscal, elusión, Fraude de Ley Tributaria y evasión.

Villanueva Walker (2017) sobre la planificación fiscal señala lo siguiente:

La planificación fiscal agresiva no se identifica con la elusión, las estructuras de planificación calificadas como agresivas son posibles debido a la falta de armonización de las normas tributarias en el mundo, lo que permite a las Multinacionales organizar el pago de sus impuestos usando los vacíos o falta de coherencia entre las normas de distintos estados (pág. 244)

Las Ventajas y Desventajas de los Paraísos Fiscales se pueden establecer dependiendo del punto de vista de las empresas y personas naturales, o del País de donde se trasladan los beneficios.

\section{$\underline{\text { Las Ventajas para las empresas y personas naturales }}$}

Los territorios de baja o nula imposición les ofrecen las siguientes ventajas:

- Creación de empresas offshore con facilidad para los no residentes

- Tasa Nominal de Impuesto reducida o no hay tasa nominal para los no residentes que constituyeron las empresas en dicho territorio, siempre que no realicen actividad dentro del mismo.

- La protección de activos

- Sistema judicial Independiente, algunos de ellos basados en el sistema anglosajon Common Law

- Uso de moneda fuerte (divisas), asimismo hay ausencia de control de cambios para no residentes

- Tienen una determinada estructura financiera, especialmente bancaria, asimismo cuenta con secreto bancario

- Usualmente tienen estabilidad social, económica y política que les proporciona un alto nivel de confianza a los capitales que se invierten o se alojan en dichos países o territorios

- Cuentan con vías de acceso, transporte y comunicaciones bien desarrolladas. 
Falcon y Tella, y Pulido Guerra (2010) en su libro Derecho Fiscal Internacional sobre los Centros off shore señalan que se refiere a territorios donde se aplica regímenes beneficiosos que no está al alcance de los residentes de la jurisdicción:

a) La expresión «centros off shore» o centros «extraterritoriales» se utiliza para referirse a los territorios en los que se concentra una intensa actividad económica o de inversión de no residentes, de modo que el peso de la actividad extraterritorial es muy superior al de la actividad doméstica.

Literalmente, podría considerarse como off shore o extraterritorial cualquier actividad o inversión realizada en el extranjero (en un país distinto al de residencia), pero la expresión se reserva usualmente para referirse a territorios donde se aplica un régimen especialmente beneficioso, que normalmente no está al alcance de los residentes en dichos territorios (pág. 257)

\section{Desventajas para las empresas y personas naturales}

- En los Territorios de baja o nula imposición tambien operan empresas que realizan evasión y elusión de impuestos y lavado de activos, esto origina prejuicio de parte de los Estados hacia las operaciones que se realizan en estas jurisdicciones.

- Los gastos provenientes de esos países no son deducibles para los contribuyentes

- La tasas de retención puede ser más elevadas.

\section{Las Desventajas en los países y estados de donde se trasladan los beneficios}

- Erosión de la Base Tributaria por planificación fiscal, elusión o evasión, BEPS "señala que la existencia de lagunas o mecanismos no deseados entre los distintos sistemas impositivos nacionales" constituye un grave riesgo para los ingresos tributarios, lo mismo señala el Parlamento Europeo.

- La menor recaudación de impuestos origina que los países no puedan prestar en forma adecuada los servicios de educación, salud y otros especialmente en los países en Desarrollo.

- Competencia Fiscal Perjudicial

- Distorsión del comercio y las inversiones 
La Resolución del Parlamento Europeo (2015) se pronuncia sobre como la elusión y evasión fiscal a traves de paraísos fiscales son obstáculos en los países de desarollo, en el inc. h) de su resolucion indica lo siguiente:

Considerando que los paraísos fiscales y las jurisdicciones opacas que permiten la no divulgación de la información bancaria o financiera, junto con regímenes que aplican impuestos nulos para atraer capital e ingresos que deberían haber sido gravados en otros países, crean una competencia fiscal perjudicial, minan la equidad del sistema fiscal y distorsionan el comercio y las inversiones, y afectan en particular a los países en desarrollo, con una pérdida estimada en 189,000 millones de ingresos fiscales anuales (pág. 60)

\subsubsection{Casos Prácticos de Traslado de Beneficios a Países o Territorios de Baja o Nula} $\underline{\text { Imposición }}$

Picón Gonzales (2016) señala que hay cuatro modos de utilización de los Paraísos Fiscales a fin de lograr las mayores ventajas que pueden ofrecer estos territorios:

- $\quad$ Sociedades base (Base companies)

- Sociedades instrumentales (Conduict companies)

- Sociedades de prestaciones de servicios

- $\quad$ Sociedades de domicilio (pág. 118)

Gutierrez de Pablo (2015) en su tesis de doctorado señala algunos ejemplos de utilización de los Paraísos Fiscales para personas físicas y persona jurídicas:

a) Son ejemplos de modos de utilización de Paraísos Fiscales en personas físicas los siguientes:

- Cambio de residencia y domicilio fiscal.

- Las sociedades de artistas.

- $\quad$ El fraccionamiento de los sueldos de los altos directivos (pag 328-332)

b) Son ejemplos de modos de utilización de Paraísos Fiscales en personas jurídicas los siguientes: 
- Manipulación del precio

- Utilización de compañías base y de compañías instrumentales

- Subcapitalización

- Financial Pivots y Compañías cautivas

- Transportes Marítimos

- $\quad$ Sociedades de servicios

- $\quad$ Empresas comisionistas (pag 333-347)

$\underline{\text { Manipulación de precio - Ejemplo: }}$

La sociedad de Costa Rica importa productos X, los productos son exportados de Perú a Costa Rica, pero la facturación es realizada en Aruba por una empresa del mismo grupo que la sociedad Peruana y Costa Rica. La empresa de Costa Rica paga a las empresas de Aruba, por los productos X enviados desde el Perú. Las facturaciones de la sociedad de Aruba permiten mejorar sensiblemente los precios y localizar el beneficio en Aruba (p335)

\section{Utilización de compañías base y de compañías instrumentales Ejemplo 1:}

Un tipo de compañía base utilizada para elusión es la "Holding" administradora de activos, como se describe en el ejemplo:

Uno de los tipos más comunes de elusión o evasión fiscal de las compañías base es el de simple "Holding" administradora de activos.

El operador transfiere el rendimiento generado por los activos a la Sociedad Base, ahorrando impuestos en distintas fases. Veamos un ejemplo una sociedad residente en Gran Bretaña, con un alto tipo impositivo por el impuesto de sociedades, adquiere acciones u otros activos mobiliarios o inmobiliarios a través de una compañía situada en Gibraltar o bien crea simplemente un trust u otro sistema aportando los activos a la compañía Gibraltareña. La Compañía Gibraltareña adquiere un complejo turístico en España con los rendimientos obtenidos en el Paraíso Fiscal, con lo cual se elude la tributación de rendimientos obtenidos, en Gran Bretaña. (Gutierrez de Pablo pag 336) 
Utilización de compañías base y de compañías instrumentales Ejemplo 2:

Un ejemplo del uso de una compañía instrumental para elusión se describe en el siguiente ejemplo:

Por la estrategia de las sociedades instrumentales, una compañía residente en el país A recibe intereses, dividendos o regalías procedentes del país $\mathrm{B}$, sin retención o bajo una imposición reducida por aplicación del convenio entre ambos países. La compañía referida está dominada por una persona o entidad residente en el país C, que no tiene convenio con B pero sí con A. (Picon Jorge p 126)

\subsection{OCDE: Posiciones y Acuerdos Realizados con los Paraísos Fiscales}

En 1998, la OECD estableció una serie de factores para identificar los paraísos fiscales en su informe "Report Harmful Tax Competition: An Emerging Global Issue", los cuales fueron descritos en párrafos anteriores.

Según la OCDE en su informe "Countering Offshore Tax Evasion Some Questions and Answers”, en junio del 2000 se identificó más de 40 países que cumplían con los criterios de Paraíso Fiscal.

La lista de paraísos fiscales publicada en el año 2000 estaba compuesta por aquellas jurisdicciones que cumplían con los criterios descritos en el Informe de 1998 de la OCDE "Report Harmful Tax Competition: An Emerging Global Issue”.

Esta lista de paraísos fiscales no cooperantes estaba conformada por jurisdicciones que no habían asumido los compromisos formales con la OCDE, luego de que se les solicitó hacerlo.

Del año 2000 al 2002, 31 jurisdicciones se comprometieron formalmente a implementar los estándares de transparencia e intercambio de información establecidos por la OCDE.

Sin embargo, siete jurisdicciones no firmaron dicho compromiso y el Comité de Asuntos Fiscales de la OCDE en abril del 2002 las incluyó en la lista de paraísos fiscales no cooperantes: Andorra, el Principado de Liechtenstein, Liberia, el Principado de 
Mónaco, la República de las Islas Marshall, la República de Nauru y la República de Vanuatu.

Posteriormente, dichas jurisdicciones firmaron los compromisos correspondientes con la OCDE y fueron eliminadas de la lista de paraísos fiscales no cooperativos.

Tiempo después firmaron compromisos con la OCDE las jurisdicciones de Nauru y Vanuatu s en 2003 y Liberia y las Islas Marshall en 2007.

Para el año 2007, la gran mayoría de ellos se comprometió a implementar la transparencia y el intercambio efectivo de información para que la OCDE no las consideren jurisdicciones poco cooperantes.

En el año 2009, el Comité de Asuntos Fiscales de la OCDE eliminó las jurisdicciones de Andorra, Mónaco y Liechtenstein de la lista de paraísos fiscal no cooperantes, porque se comprometieron a implementar los estándares internacionales de transparencia fiscal e intercambio de información. (OECD, Centre for Tax Policy and Administration;, 2009, pág. 12)

\subsection{BEPS: La Erosión de las Bases Tributarias y el Desvío de Utilidades}

BEPS son las siglas de "Base Erosion and ProfitShifting" el cual es un Plan de Acción que ha sido diseñado y publicado por la OCDE en el 2013, para combatir la erosión de las bases tributarias y el desvío de utilidades.

Según la OCDE, esta erosión se origina por la existencia de vacíos o mecanismos no deseados entre los diferentes sistemas impositivos de cada país de los que pueden aprovecharse las empresas multinacionales.

BEPS (2013) estableció 15 acciones a realizer que son las siguientes:

- Acción 1: Abordar los retos de la economía digital para la imposición

- Acción 2 Neutralizar los efectos de los mecanismos híbridos

- Acción 3 Refuerzo de la normativa sobre CFC

- Acción 4 Limitar la erosión de la base imponible por vía de deducciones en el interés y otros pagos financieros 
- Acción 5 Combatir las prácticas fiscales perniciosas, teniendo en cuenta la transparencia y la sustancia.

- Acción 6 Impedir la utilización abusiva de convenios fiscales.

- Acción 7 Impedir la elusión artificiosa del estatuto de establecimiento permanente $(\mathrm{EP})$

- Acciones 8 - 10 Asegurar que los resultados de los precios de transferencia están en línea con la creación de valor.

- Acción 11 Evaluación y seguimiento de BEPS.

- Acción 12 Exigir a los contribuyentes que revelen sus mecanismos de planificación fiscal agresiva.

- Acción 13 Reexaminar la documentación sobre precios de transferencia.

- Acción 14 Hacer más efectivos los mecanismos de resolución de controversias.

- Acción 15 Desarrollar un instrumento multilateral que modifique los convenios fiscales bilaterales (OCDE/G20, 2015)

La movilidad de los capitales y de los activos tales como la propiedad intelectual que es un intangible, así como de los nuevos modelos de negocio se ha convertido en un serio problema, al respecto la OCDE señala lo siguiente:

La recaudación del impuesto sobre sociedades se efectúa a nivel nacional. En los casos de actividades económicas transnacionales, la interacción entre distintos sistemas impositivos nacionales puede derivar en la imposición por parte de más de una jurisdicción, o doble imposición. Las actuales normas impositivas internacionales fueron confeccionadas para evitar tal situación.

Sin embargo, estas mismas normas han facilitado, en algunos casos, el caso contrario, por ejemplo, la doble no imposición. A su vez, la interacción entre los sistemas impositivos nacionales puede provocar resquicios o lagunas que impiden la imposición de beneficios en una ubicación específica (renta apatrida) (OECD.ORG, 2019, pág. 1)

Como señalamos en párrafos posteriores, la Unión Europea emitió una Resolución donde señalaba que los países en desarrollo eran los más perjudicados por la erosión de las Bases fiscales, al respecto la OCDE señala lo mismo: 
BEPS resulta de gran pertinencia para los países en desarrollo debido a la fuerte dependencia de las rentas del impuesto sobre sociedades, en particular de las empresas multinacionales (EMN). Cerca de 80 países en desarrollo y economías de otros Estados no miembro de la OCDE o del G-20 han sido consultados y más de una docena participa de manera directa en el Comité de Asuntos Fiscales, junto con organizaciones regionales en materia fiscal, tales como el Foro Africano de Administración Tributaria (ATAF). Los retos específicos a los que se enfrentan los países en desarrollo, identificados por los propios países, se abordan a lo largo de los trabajos de BEPS. (OECD.ORG, 2019, pág. 2)

La OCDE para combatir los paraísos físcales estableció que ellos deben comprometerse a implementar la transparencia y el intercambio efectivo de información, de esta manera la OCDE no las consideran jurisdicciones poco cooperantes.

Pero en la práctica esto tiene sus limitaciones; por ese motivo, en el Plan BEPS se está trabajando con los países en desarrollo para establecer colaboraciones entre auditores fiscales con el objeto de mejorar las auditorías y luchar contra la erosión, al respecto la OCDE señala lo siguiente:

Existe, además, una rama de trabajo consagrada al desarrollo de pautas de carácter práctico para los asuntos más prioritarios de BEPS señalados por los países en desarrollo, incluyendo las herramientas de apoyo para su aplicación. La nueva iniciativa conjunta entre la OCDE y el Programa de las Naciones Unidas para el Desarrollo, denominada Inspectores Fiscales sin Fronteras, permitirá la colaboración entre auditores fiscales experimentados y oficiales en materia fiscal de países en desarrollo en casos reales de auditoría fiscal, con el fin de mejorar los resultados reales y reforzar la capacidad de auditoría fiscal. (OECD.ORG, 2019, pág. 2)

El plan de acción BEPS ha identificado 15 acciones prioritarias para combatir la erosión de las bases tributarias y el desvio de utilidades, una de ellas es el fortalecimiento de las reglas CFC, sin embargo Villagra Renee (2013) señala lo siguiente:

No obstante, la reciente posición de la OCDE en el Congreso de la IFA llevado a cabo en Copenhague en agosto de 2013, que trató el tema del gravamen de las rentas pasivas de los grupos empresariales, se llegó a una conclusión muy interesante, y quizás no novedosa para los países que cuentan con la legislación 
CFC hace tiempo. Y es que, si bien la citada legislación tiene el objetivo de prevenir la elusión fiscal, raramente es aplicada en la práctica (p 55)

Respecto a la lucha contra la erosión de la base imponible y el traslado de beneficios la OCDE (2013) se publicó un libro del mismo nombre en el que señala que "La erosión de bases imponibles constituye un grave riesgo para los ingresos tributarios, la soberanía fiscal y la equidad tributaria, tanto de los Estados miembros de la OCDE como de los no miembros”. (OCDE, 2013, pág. 7)

La erosión de las bases imponibles dentro de cada Estado puede ser interna o externa, pero no cabe duda que una parte significativa de la erosión es el traslado de beneficios al exterior.

\subsubsection{Principios de la Imposición de las actividades Transfronterizas y Erosión de las Base Imponibles - OCDE}

Sobre los principios fundamentales de la imposición de las actividades transfronterizas, la OCDE (2013) señala que estos se encuentran principalmente en las legislaciones tributarias nacionales, Convenios de Doble Imposición e Instrumentos de Derecho Internacional que permiten combatir la erosión de las bases imponibles y el traslado de beneficios.

Estos principios fundamentales de la imposición de las actividades transfronterizas son los siguientes:

- $\quad$ Potestad Tributaria

- Precios de Transferencia

- Endeudamiento

- Disposiciones Antielusion

a) Potestad Tributaria

La potestad tributaria se basa en que para gravar una renta obtenida por un contribuyente, se establece un criterio de conexión entre la Renta obtenida con dicho país o territorio.

En el mundo los sistemas tributarios se dividen entre mundiales y territoriales, así tenemos a i) países que someten a tributación rentas percibidas en todo el mundo por sus 
residentes, es decir las rentas obtenidas dentro y fuera de su país y ii) países que gravan las rentas obtenidas en su jurisdicción.

Por lo general, los países y territorios aplican estos factores de conexión en forma combinada, porque si bien es importante la residencia del contribuyente, también lo es el origen de la fuente de riqueza.

Esto origina que muchas veces las rentas de las empresas y personas naturales puedan ser gravadas en varios países, produciéndose la doble imposición, los Estados suelen firmar Convenios de Doble Imposición y/o legislar en sus normas internas medidas que solucionen ese problema; sin embargo, en ese proceso de resolver las diferencias de los regímenes tributarios de los diversos países, pueden producirse situaciones que las empresas y personas naturales lo utilicen para tener doble exención de dichas rentas.

La OCDE (2013) señala que los convenios en sus disposiciones utilizan la conexión del establecimiento permanente para determinar si procede gravar o no los beneficios de un contribuyente no residente; no obstante, existen beneficios que pueden ser gravados en un país aun cuando la empresa o persona natural no opere en el debido al concepto del origen de la fuente. Las rentas gravadas pueden ser las siguientes:

- Rentas Derivadas de Bienes Inmuebles

- Las Rentas como dividendos, intereses, canones o regalias, honorarios por servicio técnicos

- Los beneficios obtenidos por primas de seguros

- La prestación de servicios si el proveedor cumple determinadas condiciones (págs. 39-42)

La OCDE además señala que el "Informe de los Economistas designados por la Sociedad de Naciones" emitida en 1923 establece que el origen y producción de la riqueza están conformadas por todas las etapas de la creación de la misma y sus factores esenciales son:

- $\quad$ El origen de la Riqueza (La fuente)

- El lugar donde se invierte (La Residencia) 
En todas estas etapas en que se concreta la riqueza pueden participar diversas autoridades territoriales.

LA OCDE se adhiere al referido Informe y agrega que "el principio del Origen de la riqueza continua siendo en la actualidad el fundamento principal de la tributación" (OCDE, 2013, pág. 42)

\section{b) Precios de Transferencia}

Los Precios de Transferencia se basan en el principio de plena competencia que estipula que las empresas vinculadas deben distribuir sus ingresos como si se tratara de terceros independientes en circunstancias similares.

La correcta determinación de los precios en las operaciones entre vinculadas evita el traslado de los beneficios y permite que cada país grave el beneficio que le corresponde, la OCDE señala lo siguiente:

La Cuestión de la jurisdicción tributaria está estrechamente relacionada con el cálculo de los beneficios: después de determinar que una parte de los beneficios de una empresa proceden de un país y que ese país debería tener derecho a gravarlos, es necesario establecer normas para determinar la proporción de los beneficios que estará sujeto al impuesto (OCDE, 2013)

Este principio de plena competencia se encuentra plasmado en la mayoría de las legislaciones del mundo y "esta recogido en los artículos 7 y 9 de convenios fiscales de la OCDE y las Naciones Unidas, así como en la práctica totalidad de los convenios de doble imposición”. (OCDE, 2013, pág. 43)

\section{c) Endeudamiento}

La Deuda que tiene una empresa corresponde a recursos que no son propios, el cual es diferente a los aportes de capital que hacen los accionistas.

En el primer caso se pagan intereses por el préstamo obtenido, el cual es deducible para el Impuesto a la Renta, en el segundo caso se abonan dividendos al accionista el cual no es deducible. 
El principio es establecer las normas que impidan que los aportes de capital puedan ser colocados como prestamos de los accionistas y empresas vinculadas y se los deduzcan en la determinación del Impuesto a la Renta.

d) Disposiciones Antielusión

Los países utilizan una variedad de estrategias para luchar contra la elusión fiscal de tal forma que puedan garantizar la equidad y la eficacia en sus regímenes tributarios.

El objetivo de las estrategias es obtener información oportuna para determinar cuales son las medidas que se tienen que utilizar para disuadir a los contribuyentes de la planificación fiscal agresiva.

El objetivo final de las estrategias de respuesta es reprimir las actividades de elusión fiscal con medidas normativas e influir en los comportamientos del contribuyente en el futuro.

Entre los sistemas tributarios nacionales se tienen las siguientes normas de lucha contra la elusión fiscal:

- Las Normas o doctrinas generales de lucha contra la elusión

- Las normas relativas a las corporaciones foráneas controladas (CFC)

- Las normas de subcapitalización y otras normas que limitan las deducciones de intereses

- Las Normas destinadas a luchar contra los mecanismos híbridos

- Las Normas de lucha contra la erosión de la Base Imponible que establecen retenciones en la fuente o prohibición de deducciones

En los convenios de doble imposición se consignan normas antielusivas para reducir el riesgo de un uso indebido de los mismos:

- Prohibición de la aplicación de los beneficios de los convenios a determinadas entidades

- Disposiciones a determinadas categorías especiales de ingresos

- Disposiciones contra los regímenes preferentes establecidos después de la firma del convenio 
- Disposiciones para proteger la Base Imponible de los países que suscriben convenios con países de una tributación reducida

- Disposiciones para evitar la doble exencion (OCDE, 2013, págs. 45-46)

\section{Principios Fundamentales y posibilidades de erosión de la Base Imponible y Traslado de Beneficios}

Según la OCDE (2013) las empresas Multinacionales tienen sedes en diversos países y por lo general en sus actividades de erosión de la Base imponible y traslado de beneficios, desplazan los mismos a los países o territorios cuya tributación es más reducida y trasladan los gastos a los países donde los impuestos son más elevados, con el objeto de maximizar la deducción. Asimismo, utilizan estrategias para aprovechar los créditos tributarios, traslado de pérdidas y repatriación de capitales (pág. 46), mediante la utilización y aprovechamiento de las normas basadas en los principios descritos en párrafos anteriores:

- Competencia Tributaria

- $\quad$ Precios de Transferencia

- Endeudamiento

- Reglas Antielusion

- Análisis de las estructuras empresariales de planificación fiscal

Respecto a la Competencia Tributaria la OCDE (2013) señala que es importante examinar los sistemas tributarios con el objeto de suprimir los obstáculos a la inversión y al comercio transfronterizo, sin embargo se debe analizar los mismos para reducir el riesgo de exención involuntaria a través de los regímenes tributarios nacionales o los convenios de doble imposición.

Las maneras que las empresas pueden aplicar las normas vigentes para reducir al mínimo o suprimir su carga tributaria en el ámbito de la financiación son las siguientes:

- Utilización de una filial de baja tributación en el exterior

- Utilización de entidades Hibridas 
- Utilización de Instrumentos financieros híbridos y de otras operaciones financieras

Asimismo, se puede reducir o suprimir el gravamen del beneficio en la fuente mediante la interposición de entidades intermediarias en los países firmantes de un convenio de doble imposición, con el objeto de solicitar los beneficios de dicho convenio de la siguiente manera:

- Sociedades Instrumentales

- Instrumentos Derivados (OCDE, 2013)

Respecto al análisis de las estructuras empresariales de planificación fiscal, la OCDE (2013) señala que las estructuras cuyo objeto es erosionar la base imponible y el traslado de beneficios en sus estrategias tienen los siguientes elementos:

i. Reduccion al minimo de la tributación en el país de origen o país extranjero donde la empresa operativa esté implantada (que a menudo es un país extranjero o territorio con una tributacion media o elevada) bien sea mediante un traslado de los beneficios brutos por conducto de estructuras comerciales o mediante una reduccion del beneficio neto al aumentar al maximos las deducciones a favor del contribuyente.

ii. Retención en la Fuente reducida o exención en dicha retención.

iii. Tributación reducida o exención del tributo a favor del beneficiario (que puede obtenerse mediante países o territorios de baja tributación o mediante regímenes preferenciales o mecanismos híbridos) con la posibilidad de obtener frecuentemente considerables beneficios excepcionales mediante acuerdos intragrupos.

iv. Exención del impuesto sobre los beneficios escasamente gravados (lograda en las tres primeras etapas) a nivel de la Sociedad matriz basica

v. La estrategias de repatriacion de dinero en efectivo del extranjero (pág. 53)

La OCDE (2013) señala que el análisis de las estructuras empresariales le permite establecer las siguientes observaciones:

- Su efecto global es que cada día hay una mayor proporción de beneficios afectada por estructuras jurídicas artificiosas y derechos y obligaciones de carácter intangible, igual que se tiende a transmitir legalmente el riesgo 
intragrupo, con el resultado de reducir la parte de los beneficios asociados a operaciones concretas.

- Si bien desde un punto de vista técnico estas estrategias empresariales de planificación fiscal pueden ser lícitas y aprovechan interacciones cuidadosamente estudiadas entre diversos principios y normas tributarias, su efecto global es erosionar la base imponible del impuesto sobre las sociedades de numerosos países incumpliendo los objetivos previstos por la política nacional. (págs. 53-54)

Este informe recomienda la elaboración de un plan de acción a escala mundial para resolver el problema de la erosión de la base imponible y el traslado de beneficios. 


\section{CAPÍTULO II: MARCO LEGAL PERUANO}

\section{Territorio de Baja o Nula Imposición en la LIR}

\subsubsection{Países o territorios de Baja o Nula Imposición}

El Perú utiliza dos maneras de calificar si un país, territorio o estado es de Baja o Nula Imposición:

- Una lista cerrada

- Que un país, estado o territorio cumpla alguna de las características señaladas en las Ley y reglamento de la LIR: Art 44 inc. m) de la LIR, Art. 86 y 87 del Reglamento y Anexo "Lista de Países o Territorios de Baja o Nula Imposición"

Los Paraísos fiscales o centros offshore legalmente son denominados en la Ley del Impuesto a la Renta como Países o territorios de baja o nula imposición hasta el $31 / 12 / 2018$.

Según las últimas modificatorias de la LIR y que están vigentes a partir del 2019, se introdujeron los siguientes cambios:

- El término "países o territorios de baja o nula imposición" es modificado por "países o territorios no cooperantes o de baja o nula imposición" en los artículos 5-A, 10, 14-A, 32, 32-A, Art. 44, 51, 55 A, 112 y 114 de la LIR.

- Asimismo incluyeron el concepto "realizan con sujetos cuyas rentas, ingresos o ganancias provenientes de dichas transacciones están sujetos a un régimen fiscal preferencial".

- Respecto al Anexo de Países o Territorios no cooperantes o de Baja o Nula Imposición: En el nuevo Anexo se incorpora a las jurisdicciones de Curazao, Guam, Islas Monserrat, Republica de Trinidad y Tobago y Sint Maarten, asimismo se elimina de dicha lista a Alderney, Antillas Neerlandesas, Aruba, Luxemburgo, Madeira y Monserrat. 


\subsubsection{Calificación de países o territorios no cooperantes o de baja o nula imposición}

En el Perú, la LIR y Reglamento vigente hasta el 31/12/2018 estableció el concepto de País o Territorio de baja o Nula Imposición, definiéndolos a través de una lista cerrada en un anexo; y por otro lado, estipuló que se considera país o territorio de baja o nula imposición a aquel donde la tasa efectiva del Impuesto a la Renta, cualquiera fuese la denominación que se dé a este tributo, sea cero por ciento $(0 \%)$ o inferior en un cincuenta por ciento $(50 \%)$ o más a la que correspondería en el Perú sobre rentas de la misma naturaleza, de conformidad con el Régimen General del Impuesto, y que, adicionalmente, presente al menos una de las características estipuladas en el artículo 86 del Reglamento de la LIR.

En el año 2018 se modificaron estos conceptos con el Decreto Legislativo 1381.

Según la exposición de motivos del Decreto Legislativo No 1381, la LIR solamente contemplaba el concepto de País o Territorio de Baja o Nula Imposición, pero no el de países o territorios no cooperantes o regímenes fiscales preferenciales, por lo tanto, las medidas antielusivas existentes no se podían aplicar con operaciones elusivas realizadas con dichas jurisdicciones, al respecto la exposición de motivos señala lo siguiente:

Sin embargo, toda vez que la LIR solo considera el concepto de PTBNI, las medidas defensivas existentes en la LIR señaladas en el acápite anterior no pueden ser aplicables contra operaciones con fines elusivos que involucren figuras diferentes de un PTBNI, como es el caso de los países o territorios no cooperantes.

En ese sentido, es posible afirmar que la legislación vigente no cumple cabalmente con el objetivo para la que fue emitida, pues no protege la base tributaria peruana de los "paraísos fiscales", sino solo de una forma de ellos. (Direccion General de Politicas Ingresos Publico, MEF, 2018, pág. 16)

Como ya señalamos en párrafos anteriores, la OCDE en el año 2000 publicó una lista de paraísos fiscales que estaba compuesta por países no cooperantes que no asumieron los compromisos formales con la OCDE luego de que esta les solicitó hacerlo. Al respecto, en la exposición de motivos señalan lo siguiente: 
Así pues, la OCDE estableció en un reporte emitido en el año 2000 una lista de jurisdicciones "no cooperantes", basándose en los principios de transparencia e intercambio de información con fines tributarios. (Direccion General de Politicas Ingresos Publico, MEF, 2018, pág. 17)

Los países o territorios denominados como "no cooperantes" son aquellas jurisdicciones que tienen ausencia de transparencia e intercambio de información.

Es importante señalar que en diciembre de 2017, la Unión Europea publicó la primera lista de países y territorios no cooperantes en materia fiscal que fue aprobada en Bruselas por los Ministros de Finanzas de los Estados Miembros de la UE, se incluyó a 17 países: American Samoa, Bahrain, Barbados, Grenada, Guam, Korea (Republic of), Macao SAR, Marshall Islands, Mongolia, Namibia, Palau, Panama, Saint Lucia, Samoa, Trinidad and Tobago, Tunisia y United Arab Emirates por no respetar las normas acordadas. Los datos de esta publicación son las siguientes:

The Council, at its meeting on 5 December 2017, adopted the Council conclusions on the EU list of non-cooperative jurisdictions for tax purposes, that are set out in the Annex. (General Secretariat of the Council, 2017, págs. 8-12)

Asimismo, 47 países se comprometieron a subsanar las deficiencias de sus sistemas tributarios y a cumplir los criterios requeridos por la Unión Europea, esto fue publicado en la web de la European Comission:

Esta iniciativa sin precedentes debería aumentar el nivel de buena gobernanza fiscal a escala mundial y contribuir a la prevención de los abusos fiscales a gran escala revelados por recientes escándalos como el de los «papeles del paraíso» (Comisión Europea - Comunicado de prensa, 2017)

En la Exposición de motivos del Proyecto de Decreto Legislativo No 1381 señala que la Unión Europea elaboró la lista considerando el nivel de transparencia fiscal, tributación justa e implementación de estándares BEPS, asimismo indica lo siguiente:

Respecto de las operaciones con dichos países o territorios, los Estados miembros de la UE deben aplicar medidas administrativas como el seguimiento reforzado de las transacciones que involucren a países no cooperantes, incremento del riesgo de ser auditado para los contribuyentes que se beneficien de operaciones con países no cooperantes, o, incremento del riesgo de ser auditado para los contribuyentes que utilicen estructuras o dispositivos en los que 
intervengan los países y territorios no cooperadores. Asimismo, los países miembros de la UE pueden aplicar medidas legales defensivas adicionales, tales como la no deducibilidad de costes, aplicación de normas relativas a las sociedades extranjeras controladas, requerimiento de documentación adicional, entre otras. (Direccion General de Politicas Ingresos Publico, MEF, 2018, pág. 18)

En el Perú la LIR y Reglamento vigente hasta el 31/12/2018, señalaba que para ser país o territorio de Baja o Nula Imposición además que la carga impositiva sea menor a la que correspondería en el Perú tenia que tener al menos una de las siguientes características:

a) Que no esté dispuesto a brindar información de los sujetos beneficiados con gravamen nulo o bajo.

b) Que en el país o territorio exista un régimen tributario particular para no residentes que contemple beneficios o ventajas tributarias que excluya explícita o implícitamente a los residentes.

c) Que los sujetos beneficiados con una tributación baja o nula se encuentren impedidos, explícita o implícitamente, de operar en el mercado doméstico de dicho país o territorio.

d) Que el país o territorio se publicite a sí mismo, o se perciba que se publicita a sí mismo, como un país o territorio a ser usado por no residentes para escapar del gravamen en su país de residencia (Decreto Supremo N. ${ }^{\circ}$ 258-2012-EF, 2012)

La exposición de motivos señala que estas características necesitan actualizarla a los estándares internacionales en los ámbitos de transparencia e intercambio de información establecido por la OCDE, porque el Perú, al encontrarse en su Marco Inclusivo, se ha comprometido a cumplir con los estándares exigidos por BEPS.

El país necesita proteger la base tributaria, pero sin que eso implique perjudicar al contribuyente, en caso de que realice operaciones reales con los países o territorios de baja o nula imposición.

Como señalamos en párrafos anteriores, para el año 2007, la gran mayoría de las jurisdicciones considerados Paraísos Fiscales se comprometieron a implementar la 
transparencia y el intercambio efectivo de información para que la OCDE no las considere jurisdicciones poco cooperantes.

Reiteramos que la Comisión de Asuntos Fiscales, en el año 2009, decidió eliminar de la lista de paraísos fiscales no cooperantes a las jurisdicciones de Andorra, el Principado de Liechtenstein y el Principado de Mónaco, porque se comprometieron a implementar las normas de transparencia e Intercambio de información de la OCDE, actualmente el Comité de Asuntos Fiscales no tiene jurisdicciones catalogadas como un paraíso fiscal no cooperante. (OECD, 2019)

Como se podrá observar, la Transparencia Fiscal y el Intercambio de Información son compromisos que han firmado los Países de Territorios de Baja o Nula Imposición para no ser considerados como Paraisos Fiscales No cooperantes, por ese motivo el MEF ha visto la necesidad de incluir este concepto en la Ley del Impuesto a la Renta.

Sobre los acuerdos de Intercambio de Información se desarrollará en párrafos posteriores.

\subsubsection{Calificación de Regímen Fiscal Preferencial}

Las modificaciones vigentes a partir del 01/01/2019 también incluyeron el concepto "Sujetos a un Régimen Fiscal Preferencial" los cuales tienen los mismos límites y restricciones que los países fiscales no cooperantes o de baja o nula imposición.

La OCDE señala que "Un régimen fiscal preferencial es aquel que otorga algún tipo de beneficio fiscal en comparación con otros países, por ejemplo tasas de impuestos menores, reducciones a la base gravable o condiciones especiales para el pago de gravámenes.” (PRODECON, 2018, pág. 16)

Asimismo, la OCDE/G20 (2015) en el Resumen del Informe Final, señala que "Las preocupaciones actuales son el riesgo que supone la utilización de regímenes fiscales preferenciales para transferir artificialmente los beneficios y por la falta de transparencia en lo que respecta a ciertos tax ruling (decisiones administrativas en relación a contribuyentes específicos)" (OCDE/G20, 2015, pág. 21)

La Exposición de motivos del Decreto Legislativo No 1381 señala que "la Acción 5 del Proyecto BEPS de la OCDE tiene como objetivo combatir las prácticas fiscales 
perniciosas, considerando el riesgo que supone la utilización de "regímenes fiscales preferenciales" para transferir artificialmente los beneficios" (Direccion General de Politicas Ingresos Publico, MEF, 2018, pág. 20)

Como señalamos anteriormente, la OECD (1998, págs. 26-35) en su Informe Harmful Tax Competition estableció cuatro factores considerados clave para identificar Régimen Fiscal Preferencial (preferential tax regimes):

1) No hay Impuesto Nominal o es muy bajo (No or low effective tax rates)

2) No hay actividades sustanciales en la jurisdicción. ("Ring-Fencing" of Regimes)

3) Ausencia de intercambio de información entre jurisdicciones (Lack of effective exchange of information)

4) Ausencia de Transparencia (Lack of transparency)

Luego, en el mismo informe, señala que hay otros factores que son importantes para identificar un Régimen Fiscal Preferencial que son los siguientes:

5) Una definición artificial de la base imponible (An artificial definition of the tax base)

6) Incumplimiento de los principios internacionales de precios de transferencia (Failure to adhere to international transfer pricing principles)

7) Renta de fuente extranjera exenta del impuesto de residencia del país (Foreign source income exempt from residence country tax)

8) Tasa de impuesto o base imponible negociable (Negotiable tax rate or tax base)

9) Existencia de dispositivos sobre el secreto de la información (Existence of secrecy provisions)

10) Acceso a una amplia red de tratados fiscales. (Access to a wide network of tax treaties)

11) Promoción de Regímenes como vehículos de minimización de impuestos. (Regimes which are promoted as tax minimisation vehicles) 
12) El régimen fomenta operaciones o acuerdos puramente fiscales. (The regime encourages purely tax-driven operations or arrangements)

Sobre las jurisidicciones que no califican como paraíso fiscal pero sí como régimen fiscal preferencial algunos investigadores señalan lo siguiente:

De otro lado, los regímenes fiscales perjudiciales son tratamientos tributarios nocivos inmersos en una jurisdicción que no califica como paraíso fiscal y que, en general, mantiene un nivel de imposición regular o alta. Estos regímenes ofrecen tasas efectivas bajas o nulas a no residentes o a actividades efectuadas por no residentes, lo que supone una ausencia de comunicación entre el régimen general doméstico y el especial para no residentes (ring fencing). Algunos regímenes perjudiciales han sido alojados en Suiza o Luxemburgo. (Ramos Angeles, 2015, pág. 379)

La OCDE, a mayo del 2018 estableció la existencia de 175 Regímenes Fiscales preferenciales en más de 50 jurisdicciones del mundo, por ejemplo encontró que Chile y Uruguay tienen un Régimen Fiscal preferencial cada uno, la noticia señala lo siguiente:

"De los 175 regímenes, 31 de éstos han sido cambiados; 81 regímenes requieren aún de cambios legislativos que están en progreso; se ha determinado que 47 de ellos no representan un riesgo para el Plan de Acción contra la erosión de la base impositiva y la transferencia de beneficios (BEPS, por su sigla en inglés); cuatro tienen características dañinas o potencialmente dañinas, mientras que 12 regímenes todavía están bajo revisión”, detalló la organización.

De acuerdo con el Plan BEPS, creado en el 2016 por la OCDE y el G20, aquellas jurisdicciones que sean detectadas como regímenes fiscales preferentes tendrán la oportunidad de derogar el régimen o de eliminar las características que lo vuelven “nocivo". (El Economista (México), 2018)

La Exposición de Motivos del Decreto Legislativo No 1381 señala que todos los países miembros de la Alianza del Pacifico incluyen en su legislación tributaria el concepto de regímenes fiscales preferenciales y describe cómo ha sido tratado el tema en Mexico, Colombia y Chile. Asimismo, argumenta que la legislación peruana se encuentra alejada de las tendencias internacionales en la lucha contra la elusión fiscal internacional; por ese motivo, la Administración Tributaria tiene limitaciones en sus funciones de fiscalización porque la normatividad vigente al ejercicio 2018 no es suficiente para combatir las nuevas practicas elusivas en transacciones internacionales, como por 
ejemplo, la utilización de regímenes fiscales preferenciales en el exterior. (Direccion General de Politicas Ingresos Publico, MEF, 2018, págs. 20-22)

Por eso era Importante incluir en la Ley del Impuesto a la Renta el concepto de Régimen Fiscal Empresarial.

Sobre los acuerdos de Intercambio de Información suscritos por el Perú se analizan en párrafos posteriores.

\subsubsection{Nuevos Factores en la LIR para calificar Países o territorios no cooperantes o de baja o nula imposición y Régimen Fiscal Preferencial}

En las modificatorias de la Ley del Impuesto a la Renta se estableció factores para tales calificaciones.

Los cuatro primeros son tanto calificar países o territorios no cooperantes o de baja o nula imposición y regímenes fiscales preferenciales.

- Ausencia de transparencia a nivel legal, reglamentario o de funcionamiento administrativo.

- Nulo intercambio de información o existencia de normas legales o prácticas administrativas que lo limiten.

- Inexistencia del requisito de presencia local sustantiva o del ejercicio de una actividad real o con sustancia económica.

- Imposición efectiva nula o baja.

Para calificar un Régimen Fiscal preferencial tienen 2 factores adicionales:

- Beneficios o ventajas tributarias que excluyan explícita o implícitamente a los residentes, o que los sujetos beneficiados con el régimen se encuentren impedidos, explícita o implícitamente de operar en el mercado doméstico.

- Imposición exclusiva de rentas de fuente nacional o territorial.

Respecto a estos factores cabe analizar que implica dichos conceptos tomando como base varias fuentes: 


\section{Ausencia de transparencia a nivel legal, reglamentario o de funcionamiento $\underline{\text { administrativo }}$}

La exposición de motivos del Decreto Legislativo No 1381 señala que este factor “implica que se guarden reservas respecto de información de los sujetos o de las transacciones efectuadas por estos." (Direccion General de Politicas Ingresos Publico, MEF, 2018)

La exposición de motivos del Reglamento del Decreto referido, agrega que la falta de transparencia en una jurisdicción implica que faciliten la elusión o evasión tributaria internacional, asimismo señala lo siguiente:

se puede verificar la falta de transparencia cuando, entre otros casos, se establezcan acuerdos tributarios entre la jurisdicción y el contribuyente o grupos económicos, que sean ocultos, que otorguen beneficios o ventajas diferentes a las establecidas por ley, y a los que no puedan acceder las administraciones tributarias de otras jurisdicciones (Dirección General de Políticas Ingresos Publico, MEF, 2018)

En International Law - Revista Colombiana de Derecho internacional señalan que para saber si estamos frente a un Paraíso Fiscal una de las características a analizar es la siguiente:

Ausencia de Transparencia: Ello, en el sentido de que las autoridades emiten disposiciones para evitar un efectivo intercambio de información con entidades de otros países, y de que la complejidad y confusión de la regulación emitida no permite a observadores externos o agencias fiscales de otros países entender y, por ende, controlar a los residentes que tengan relaciones económicas con entidades ubicadas en dichos territorios. (Schomberger Tibocha \& López Murcia, 2007, pág. 325)

Este factor de calificación de la norma peruana también es utilizada en la norma colombiana, la Ley 863 de 2003 adicionó el artículo 260-6 en su Estatuto Tributario, en él se estipula los criterios para expedir la lista de paraísos fiscales y con ellos llegar a definir el concepto legal de paraíso fiscal en Colombia:

“a) Se considera paraíso fiscal aquel territorio, país o jurisdicción sin impuesto a la renta o muy bajos, nominales, con respecto a lo que se aplicaría en Colombia 
en operaciones similares y que reúna cualquiera de las siguientes condiciones: ii) Falta de transparencia a nivel legal, reglamentario o de funcionamiento administrativo.” (Schomberger Tibocha \& López Murcia, 2007, pág. 332)

En el año 2012, en Colombia se reforma el Estatuto Tributario con la Ley 1607 en donde se modifica el art. 260-6 y se incluye el nuevo artículo 260-7 Paraísos Fiscales.

En el año 2016, con la Ley 1819, se modifica en el Estatuto Tributario colombiano el artículo 260-7 Jurisdicciones no cooperantes, de baja o nula imposición y regímenes tributarios preferenciales, en donde se establece que

1. Las jurisdicciones no cooperantes y de baja o nula imposición, serán determinadas con base en el cumplimiento de uno cualquiera de los criterios estipulados y 2. Los regímenes tributarios preferenciales son aquellos que cumplan con al menos dos (2) de los criterios establecidos: c. Falta de transparencia a nivel legal, reglamentario o de funcionamiento administrativo (El Congreso de Colombia, 2018)

II. Nulo intercambio de información o existencia de normas legales o prácticas administrativas que lo limiten

La exposición de motivos del Decreto Legislativo No 1381 señala que este factor “implica que la jurisdicción haga caso omiso a las solicitudes de información respecto de los sujetos o de las transacciones efectuadas por estos o que envíe información parcial, incompleta, entre otros” (Direccion General de Politicas Ingresos Publico, MEF, 2018)

La exposición de motivos del Reglamento del Decreto referido, agrega que este factor "implica que la legislación del país o territorio impida el intercambio o solo lo permita de forma parcial o incompleta" (Dirección General de Políticas Ingresos Publico, MEF, 2018)

En International Law - Revista Colombiana de Derecho internacional mencionan que para saber si estamos frente a un Paraíso Fiscal, otra de las características a analizar es:

No Intercambio de Información: Es decir, si existen leyes o prácticas administrativas que evitan un intercambio efectivo de información relevante con otros gobiernos, sobre los beneficios obtenidos por los contribuyentes en dicho territorio. (Schomberger Tibocha \& López Murcia, 2007, pág. 325) 
III. Inexistencia del requisito de presencia local sustantiva o del ejercicio de una actividad real o con sustancia económica

La exposición de motivos del Decreto Legislativo No 1381 señala que este factor “implica el análisis de la presencia, fehaciencia o sustancia de las actividades u operaciones realizadas por los sujetos" (Direccion General de Politicas Ingresos Publico, MEF, 2018)

La Exposición de motivos del Reglamento del Decreto Legislativo No 1381 menciona que se debe tener en cuenta el Plan de Acción 5 de la OCDE para evaluar este factor para determinar si un régimen fiscal es pernicioso:

Este criterio busca alinear la sustancia con la tributación de los contribuyentes a fin de que las rentas no sean artificialmente trasladadas desde los países con una mayor carga tributaria a esos con una reducida carga; y por lo tanto, que las ventajas fiscales asociadas a los regímenes preferenciales sean reconocidas únicamente si el contribuyente que aplica dichas ventajas realiza una actividad económica sustancial en el pais que las concede. (Dirección General de Políticas Ingresos Publico, MEF, 2018)

En International Law - Revista Colombiana de Derecho Internacional agregan que otra característica a analizar para saber si estamos frente a un Paraíso Fiscal es el siguiente:

No Desarrollo de Actividades Sustanciales: Consiste en la ausencia del requerimiento de que la actividad desarrollada en dicha jurisdicción sea sustancial. Lo cual evidencia que el objeto de las transacciones hechas con o en esa jurisdicción persigue de manera evidente una ventaja fundamentalmente fiscal, y que no existe interés alguno de agregar o desarrollar valor a dicha transacción o flujo de capital. (Schomberger Tibocha \& López Murcia, 2007, pág. 325)

IV. Imposición efectiva nula o baja.

La Exposición de motivos del Decreto Legislativo No 1381 señala que este factor implica que "esté determinada por una disposición legal, reglamentaria, administrativa, de una autorización, devolución o cualquier otro procedimiento". 
La Exposición de motivos del Reglamento del Decreto Legislativo No 1381 agrega que este factor de calificación es muy importante y que la tasa aplicable (anteriormente tasa efectiva) a ser comparada es el Impuesto a la Renta empresarial, la cual debe ser cero por ciento $(0 \%)$ o inferior al $60 \%$ de la que correspondería en Perú:

La ausencia de imposición tributaria o la presencia de una baja imposición constituyen el criterio fundamental para calificar a un país o territorio como de baja o nula imposición, lo cual está en función de la tasa aplicable que se impone a las empresas en dicho país o territorio en comparación con la tasa que se impone a las empresas en nuestro país. En línea con ello, se propone que la tasa aplicable a ser comparada será aquella que corresponda al impuesto a la renta empresarial. (Dirección General de Políticas Ingresos Publico, MEF, 2018)

En el caso de regímenes preferenciales, la tasa aplicable del impuesto a la renta sobre las rentas, ingresos o ganancias sujetas al régimen fiscal, cualquiera fuese la denominación que se dé a este tributo, sea cero por ciento $(0 \%)$ o inferior al sesenta por ciento $(60 \%)$ de la que correspondería en el Perú sobre rentas de la misma naturaleza a sujetos domiciliados. (Decreto Supremo No 340-2018-EF, 2018)

Picón Gonzales (2016) sobre la Imposición Nula o Baja señala lo siguiente:

Es así que desde un punto de vista técnico resulta difícil determinar objetivamente cuando un régimen fiscal puede ser calificado de paraíso fiscal, ya que podemos entender a grandes rasgos por "paraíso fiscal" al territorio o Estado que se caracteriza por una escasa o nula tributación a que someten a determinada clase de transacciones, ventas a determinadas personas o entidades que allí encuentran su cobertura o amparo (pág. 56)

Para calificar un Régimen Fiscal preferencial existe 2 factores adicionales:

V. Beneficios o ventajas tributarias que excluyan explícita o implícitamente a los residentes, o que los sujetos beneficiados con el régimen se encuentren impedidos, explícita o implícitamente de operar en el mercado doméstico.

La exposición de motivos del Decreto Legislativo No 1381 señala que es "lo que se conoce como compartimentación"

La palabra "Compartimentación" es consignada en el Libro de la OCDE “Combatir las prácticas fiscales perniciosas, teniendo en cuenta la transparencia y la 
sustancia, Acción 5 - Informe final 2015” - Proyecto de la OCDE y del G-20 sobre la Erosión de la Base Imponible y el Traslado de Beneficios” en el siguiente contexto:

Los regímenes de sedes sociales o Headquarters Regimes conceden un tratamiento fiscal preferencial a contribuyentes que ofrecen determinados servicios como, por ejemplo la gestión, coordinación o control de las actividades industriales y comerciales para un grupo en su totalidad o para miembros del grupo de un área geográfica específica. De estos regímenes pueden nacer preocupaciones sobre la compartimentación de su actividad, o porque ofrecen una definición artificial de base imponible en la medida en que los beneficios de una entidad son determinados en base al método del "coste incrementado", pero ciertos costes están excluidos del cómputo, y las circunstancias particulares no son tomadas en consideración. Aunque estos aspectos podían ser abordados por los factores existentes, estos regímenes también producen inquietudes dudas en cuanto a la sustancia (OCDE, 2016, págs. 40-42)

El mismo Libro referido en el párrafo anterior, en su versión en inglés señala lo siguiente:

These regimes may raise concerns about ring-fencing or because they provide for an artifical definition of the tax base where the profits of an entity are determined based on a "cost-plus" basis but certain costs are excluded from the basis or particular circumstances are not taken into account. (OECD/G20, 2015, págs. 40-41)

Como se podrá observar, el término compartimentación se refiere al ring-fencing, según el Glossary of Tax Terms de la OCDE el término "Ring Fence" significa lo siguiente:

RING FENCE - Theoretical enclosure established by tax legislation around certain profits, losses, transactions or groups of transactions in order to isolate them for tax purposes (OECD Home, 2019).

Entonces, la palabra "Compartimentación" se refiere al "Ring-Fencing", el "Ring Fence es el régimen fiscal preferencial que se da a ciertas ganancias, pérdidas, transacciones o grupo de transacciones, con el objeto de aislarlos con fines fiscales y que incluso se duda de que dichas operaciones tengan sustancia económica, para el caso se refiere al Headquarters Regimes ya descrito en los párrafos anteriores. 
La Exposición de motivos del Reglamento del Decreto Legislativo No 1381 señala que en las jurisdicciones donde se encuentra el régimen fiscal preferencial puede aplicarse de manera explícita o implícita; sin embargo, el país o territorio que alberga el Régimen no se ve afectado porque protege su economía:

Para que este se configure es necesario que el régimen fiscal se encuentre aislado, ya sea de forma subjetiva mediante la exclusión de sus beneficios para residentes o mediante un aislamiento objetivo que se presenta cuando se limita su aplicación a operaciones con no residentes (Dirección General de Políticas Ingresos Publico, MEF, 2018).

El Centro Interamericano de Administraciones Tributarias - CIAT sobre regímenes preferenciales señala lo siguiente:

Los paraísos fiscales son jurisdicciones que se caracterizan porque en ellos existe una nula o baja imposición fiscal efectiva respecto de las rentas de las personas físicas o jurídicas, o con relación a determinadas actividades económicas, y cuando además se verifique alguna circunstancias tales como: Existan regímenes especiales que contemplen beneficios o ventajas fiscales que no se otorguen a los residentes o que se acuerden a los no residentes privilegios o ventajas tributarias por parte de la Administración Fiscal con carácter discrecional. (Centro Interamericano de Administraciones Tributarias - CIAT, 2009)

En el numeral 2.1.3 del presente trabajo ya se realizó un análisis sobre las características de un Régimen Fiscal Empresarial desde el punto de vista de la OCDE y otras fuentes.

VI. Imposición exclusiva de rentas de fuente nacional o territorial.

La exposición de motivos señala que "implica la ausencia de imposición a las rentas de fuente extranjera"

El criterio vii) de la OCDE para identificar un régimen fiscal preferencial es: "Foreign source income exempt from residence country tax", que se refiere a aquellos países que no gravan con el Impuesto a las sociedades a las rentas de fuente extranjera, la OCDE señala que esto regímenes fiscales preferenciales pueden tener efectos nocivos para otros países. René Villagra lo explica en su publicación: 
Debemos señalar que el Reporte de la OCDE respecto a la competencia tributaria dañina, identifica los factores o características de las jurisdicciones de baja o nula imposición, -más conocidos como paraísos fiscales- y entre ellos se señala como factor clave No vii) al hecho de que la renta de fuente extranjera se encuentre exonerada de impuestos en el país de residencia. En efecto, se indica que un país que exonera de impuestos toda la renta de fuente extranjera, como por ejemplo los regímenes con sistema territorial, pueden ser particularmente atractivos desde que la exoneración reduce la tasa efectiva del impuesto a la renta y promueve la ubicación de actividades motivadas por propósitos tributarios más que por propósitos de negocios.

En tal sentido, debido a que las entidades que se benefician de esos regímenes pueden ser usadas como conductoras o para llevar a cabo triangulaciones "treaty shopping, este régimen puede tener efectos nocivos respecto a otras países (Los Convenios para evitar la Doble Imposición y Prevenir la Evasion Fiscal, págs. 31-32)

Los Factores de calificación ii), iii) iv) y v) de la norma peruana son similares a las normas colombianas, estas ya fueron descritas anteriormente. La Ley 1819 del año 2016 que modifica el Estatuto Tributario colombiano en el artículo 260-7 establece que:

1. Las jurisdicciones no cooperantes y de baja o nula imposición, serán determinadas con base en el cumplimiento de uno cualquiera de los criterios estipulados y 2. Los regímenes tributarios preferenciales son aquellos que cumplan con al menos dos (2) de los criterios establecidos:

b). Carencia de un efectivo intercambio de información o existencia de normas legales o prácticas administrativas que lo limiten.

d). Inexistencia del requisito de una presencia local sustantiva, del ejercicio de una actividad real y con sustancia económica.

a). Inexistencia de tipos impositivos o existencia de tipos nominales sobre la renta bajos, con respecto a los que se aplicarían en Colombia en operaciones similares

2) e). Aquellos regímenes a los que sólo pueden tener acceso personas o entidades consideradas como no residentes de la jurisdicción en la que opera el régimen tributario preferencial correspondiente (ring fencing)." (Estatuto Tributario Nacional, 2018) 
La OCDE (2018) sobre los principios "clave" de la transparencia y el intercambio de información con fines fiscales y los altos estándares que deben tener, establece que se puede resumir de la siguiente manera:

- Intercambio de información a solicitud cuando sea "previsiblemente relevante" para la administración y la aplicación de las leyes internas de un socio del tratado.

- No hay restricciones en el intercambio causadas por el secreto bancario o los requisitos de intereses fiscales nacionales.

- Disponibilidad de información confiable, particularmente información contable, bancaria y de propiedad, y poderes para obtenerla.

- Respeto a los derechos de los contribuyentes.

- Confidencialidad estricta de la información intercambiada (OECD, Centre for Tax Policy and Administration;, 2009, pág. 12)

En consecuencia sobre los dos primeros factores de calificación de la norma peruana para calificar países o territorios no cooperantes o de baja o nula imposición y regímenes fiscales preferenciales: I) Ausencia de transparencia a nivel legal, reglamentario o de funcionamiento administrativo y II) Nulo intercambio de información o existencia de normas legales o prácticas administrativas que lo limiten, la Administración Tributaria además de lo señalado por las normas internas, podrá considerar los altos estándares de los principios de Transparencia e Intercambio de Información para fines fiscales de la OCDE.

Asimismo, sobre la Ausencia de Transparencia y Nulo Intercambio los conceptos y características descritas en los párrafos anteriores (doctrina) ayudan a analizar si se cumple los factores de calificación que establece la norma peruana.

Reiteramos que los acuerdos de Intercambio de Información suscritos por el Perú se explicaran en párrafos posteriores.

Como se ha podido observar, la ley peruana es muy similar en algunos aspectos a las normas de Colombia. 
Si los factores de calificación de la norma peruana pueden ser identificados en una jurisdicción en forma conceptual y de acuerdo con los criterios de la OCDE, entonces debe ser considerado como un paraíso fiscal "no cooperante" o Régimen físcal Preferencial.

\subsection{Acuerdo de Intercambio de Información}

El comercio a nivel mundial se centra en grupos empresariales que operan en diversos países, por eso es sumamente importante que las Administraciones Tributarias de cada país tengan la posibilidad de usar la herramienta del intercambio de información.

En los párrafos anteriores señalamos que el tema de Acuerdo de Intercambio de Información se iba a tratar en forma separada.

\subsubsection{Acuerdos de Intercambio de Información, factor para calificar un país o territorio no cooperante de baja o nula imposición y régimen fiscal preferencial.}

En la modificación del artículo 86 del Reglamento de la LIR vigente para el 2019 se estableció otros criterios para efectos de calificar a los países o territorios no cooperantes o de baja o nula imposición y a los regímenes fiscales preferenciales como los siguientes:

- Son países o territorios no cooperantes o de baja o nula imposición los señalados en el Anexo 1 del reglamento:

Se puede incluir en el Anexo 1 a otros países o territorios, siempre que cumplan con alguno de los siguientes criterios:

a) Que no tengan vigente con el Perú un Acuerdo de Intercambio de Información Tributaria o Convenio para Evitar la Doble Imposición que incluya una cláusula de intercambio de información; o existiendo estos, no cumplan con el intercambio de información con el Perú o que dicho intercambio sea limitado por aplicación de sus normas legales o prácticas administrativas

b) Ausencia de transparencia a nivel legal, reglamentario o de funcionamiento administrativo. 
El Reglamento señala otros criterios adicionales que no consignamos porque no está relacionado al acuerdo de intercambio de información.

Ahora bien, se puede excluir de la Lista consignada en el Anexo 1 a los países o territorios no cooperantes o de baja o nula imposición que cumplan alguno de los siguientes criterios:

a) Que sean miembros de la Organización para la Cooperación y el Desarrollo Económicos - OCDE.

b) Que tengan vigente con el Perú un Convenio para Evitar la Doble Imposición que incluya una cláusula de intercambio de información.

c) Que cumplan con el intercambio de información con el Perú y que este no se encuentre limitado por aplicación de sus normas legales o prácticas administrativas.

Los miembros de la OCDE o aquellos países o territorios con los que el Perú tenga vigente un Convenio para evitar la Doble Imposición que incluya una cláusula de intercambio de información que no cumplan con el intercambio de información en los términos del inciso c) del párrafo anterior, pueden ser incluidos en el Anexo 1. (Decreto Supremo No 340-2018-EF, 2018)

- Son regímenes fiscales preferenciales aquellos regímenes que cumplan al menos dos de los 5 criterios establecidos en el articulo 86 del Reglamento de la LIR, los criterios 2.a) y 2.b) son similares a los criterios de los paraísos o territorios no cooperantes o de baja o nula imposición.

Los otros tres criterios adicionales no lo consignamos porque no están relacionados al acuerdo de intercambio de información.

\subsubsection{Países que suscribieron Convenios de Doble Imposición con el Perú}

Los Convenios de Doble Imposición (CDI) cumplen tres funciones determinantes:

- Evitar o prevenir la doble imposición mediante la asignación de potestades tributarias a los países de residencia o fuente.

- Intercambio de información entre países mediante cláusulas que faciliten dicho intercambio. 
- Prevenir la evasión fiscal mediante cláusulas que prevengan la utilización de los CDI con el único fin de aprovechar sus beneficios (treaty shopping)

El Perú suscribió convenios de doble imposición con los países de Chile Canadá, Brasil, México, Corea del Sur, Suiza y Portugal en los que establecen el acuerdo de Intercambio de Información.

En los convenios de doble imposición suscritos, los acuerdos de Intercambio de Información están estipulados en los siguientes dispositivos:

- En el CDI Perú - Chile, en el artículo 26 y sus literales 1 y 2

- En el CDI Perú - Canada, en el artículo 26 y sus literales 1 y 2

- En el CDI Perú - Brasil, en el artículo 25 y sus literales 1, 2, 3, 4 y 5

- En el CDI Perú - Mexico, en el artículo 26 y sus literales 1, 2, 3, 4 y 5

- En el CDI Perú - Corea, en el artículo 25 y sus literales 1, 2, 3, 4 y 5

- En el CDI Perú - Suiza, en el artículo 25 y sus literales 1, 2, 3, 4 y 5

- En el CDI Perú - Portugal, en el artículo 25 y sus literales 1, 2, 3, 4 y 5

El Perú suscribió la Decisión 578 de la CAN: Régimen para evitar la doble Tributación y Prevenir la Evasion Fiscal que es un Convenio Mulltilateral con Colombia, Ecuador y Bolivia.

- $\quad$ El Acuerdo de Intercambio de Informacion esta consignado en el artículo 19 de la Decision 578

Los acuerdos de intercambio de información incluidos en los Convenios de Doble Imposición solamente son efectuados por solicitud en las siguientes situaciones:

- En los CDIs suscritos con Chile, Canada, Suiza y la CAN se puede intercambiar información para aplicar lo dispuesto en el Convenio o para administrar o exigir lo dispuesto en el derecho interno de los Estados Contratantes relativo a los impuestos cubiertos por el Convenio, en el caso de Chile se incluye el IGV.

- En los CDIs suscritos con Brasil, Mexico, Corea y Portugal se puede intercambiar información de los Impuestos para aplicar lo dispuesto en el 
Convenio o para administrar y exigir lo dispuesto en la legislación nacional de los Estados Contratantes

Estos acuerdos tienen límites en cuanto a que no se puede suministrar información que no se pueda obtener sobre la base de su propia legislación o practica administrativa y no se puede obligar al otro Estado a adoptar medidas contrarias a sus normas internas.

\subsubsection{Acuerdos de Intercambio de Información suscritos con Países con los cuales no tenemos Convenios de Doble Imposición}

El Perú ha suscrito acuerdos de intercambio de información con tres países con los cuales no tenemos Convenio de Doble Imposición:

- El Convenio de Intercambio de Información Tributaria suscrito con USA en 1992.

- Acuerdo entre las Administraciones Tributarias de la República de Argentina y de la República del Perú para la Cooperación Técnica e Intercambio de Información Tributaria y Aduanera suscrito el 07/10/2004.

- Addendum al Convenio entre el Gobierno de la Republica del Perú y el Gobierno de la Republica del Ecuador para la Cooperación entre Administraciones Tributarias suscrito el 22/10/2009.

Los acuerdos de intercambio de información incluidos en los Convenios de Doble Imposición solamente son efectuados por solicitud, sin embargo en los acuerdos de intercambio de Información suscritos con Estados Unidos, con la AFIP de Argentina y el SRI de Ecuador son más amplios porque hay intercambio de información por solicitud, automática y espontánea.

Esto se puede resumir de la siguiente manera: 


\begin{tabular}{|l|c|c|c|c|c|}
\hline \multicolumn{1}{|c|}{ PAIS } & CONVENIO & TIPO DE & \multicolumn{3}{c|}{ INTERCAMBIO DE INFORMACION } \\
\cline { 5 - 6 } & O ACUERDO & CONVENIO & POR SOLICITUD & AUTOMATICO & ESPONTANEO \\
\hline CHILE & CDI & Bilateral & $\mathrm{X}$ & & \\
CANADA & CDI & Bilateral & $\mathrm{X}$ & & \\
BRASIL & CDI & Bilateral & $\mathrm{X}$ & & \\
MEXICO & CDI & Bilateral & $\mathrm{X}$ & & \\
COREA DEL SUR & CDI & Bilateral & $\mathrm{X}$ & & \\
SUIZA & CDI & Bilateral & $\mathrm{X}$ & & \\
PORTUGAL & CDI & Bilateral & $\mathrm{X}$ & & \\
CAN - Decision 5J & CDI & Multilateral & $\mathrm{X}$ & & \\
EEUU & AIIT & Bilateral & $\mathrm{X}$ & $\mathrm{X}$ & $\mathrm{X}$ \\
ARGENTINA & Acuerdo con AFIP & Bilateral & $\mathrm{X}$ & $\mathrm{X}$ & $\mathrm{X}$ \\
ECUADOR & Convenio con SRI & Bilateral & $\mathrm{X}$ & $\mathrm{X}$ & $\mathrm{X}$ \\
\hline
\end{tabular}

Fuente: CDIs y Acuerdos suscritos por el Perú

CDI $=$ Convenio de Doble Imposición

Decision 578 - Régimen para evitar la Doble Tributación y Prevenir la Evasión Fiscal

AIIT $=$ Acuerdo de Intercambio de Informacion Tributaria

AFIP = Administracion Federal de Ingresos Publicos

SRI $=$ Servicio de Rentas Internas

$\mathrm{CAN}=$ Comunidad Andina de Naciones

El Objeto del intercambio de información de los acuerdos suscritos con Estados Unidos de América, AFIP de Argentina y SRI de Ecuador son similares en algunos puntos y en otros difieren.

Las autoridades competentes de las Administraciones Tributarias Contratantes, en el marco del objeto de los acuerdos, intercambiarán información para administrar y hacer cumplir sus leyes nacionales relativas a los tributos que administran, incluida la información para:

- La determinación, liquidación y recaudación de Impuestos (1) y Tributos (2 у 3$)$

- El cobro y la ejecución de créditos fiscales (1) y creditos tributarios (2 y 3)

- La investigación o persecución de delitos fiscales o delitos que contravengan la Administración Tributaria (1) y de presuntos delitos tributarios e infracciones a las leyes y reglamentos tributarios. (2 y 3 )

En el caso del acuerdo con AFIP incluye en forma explícita el término aduanero. 
- De corresponder, la determinación de las variaciones patrimoniales, consumo o disposición de bienes. (2 y 3 )

- La determinación del valor en Aduana. (2)

(1) AAIT suscrito con Estados Unidos de América

(2) Acuerdo suscrito con AFIP de Argentina

(3) Convenio suscrito con SRI de Ecuador

Asimismo estos acuerdos incluyen el Intercambio de información espontanea, automática y especifica.

El Intercambio de Información Espontanea se produce cuando a la Autoridad competente de un Estado en el curso de sus propias actividades les llegue información que pueda ser relevante y de considerable influencia para la Autoridad competente del otro Estado y el logro del objeto o fines de los acuerdos suscritos.

El Intercambio de Información Automática se produce de manera habitual o automática a fin de cumplir lo dispuesto en sus acuerdos:

- Las autoridades competentes determinarán que Información se intercambiará en forma automatica y los procedimientos que se utilizarán para el intercambio de dicha información (AAIT con EE.UU)

- Operaciones y/o rentas gravadas, no gravadas o exentas realizadas u obtenidas en el territorio de los Estados contratantes, de las Administraciones Tributarias Contratantes (autoridades competentes), respecto de las personas y tributos comprendidos en el Acuerdo. (Acuerdo con AFIP y Convenio con el SRI)

- Informaciones generales sobre ramos de actividad económica. (Acuerdo con AFIP y Convenio con SRI)

- La información en materia de valor tendiente a determinar la veracidad o exactitud del mismo. (Acuerdo con AFIP y Convenio con SRI)

- Cualquier otro tipo de información que acuerden. (Acuerdo con AFIP y Convenio con SRI)

El Intercambio de Información Específica estipulado en el AAIT suscrito con Estados Unidos, Acuerdo con AFIP y Convenio con SRI, se realiza previa petición o 
solicitud especifica de la Administración Tributaria o Autoridad Competente del Estado requirente para los fines estipulados en el objeto de cada acuerdo.

Cuando la información que pueda obtenerse en los archivos del Estado, Administración Tributaria o Autoridad Competente requerida no sea suficiente para dar cumplimiento a la solicitud, dicho Estado, Administración o Autoridad Competente tomará las medidas permitidas por su propia legislación, incluidas las de carácter coercitivo, para facilitar al Estado, Administración u Autoridad Competente requirente la información solicitada, tales como:

a. Examinar libros, documentos, registros u otros bienes tangibles, que puedan ser relevantes, pertinentes o esenciales para la investigación;

b. Interrogar a toda persona que tenga conocimiento o que esté en posesión, custodia o control de información que pueda ser pertinente o esencial para la investigación;

c. Obligar o hacer comparecer, de acuerdo con su propia legislación, a toda persona que tenga conocimiento, o que esté en posesión, custodia o control de información que pueda ser pertinente o esencial para la investigación, a comparecer en fecha y lugar determinados, prestar declaración bajo juramento, declaración y presentar libros, documentos, registros u otros bienes tangibles.

El Acuerdo de Intercambio de Información suscrito por el Perú con los Estados Unidos de América no incluye en forma explícita la fiscalización, sin embargo permite que un representante del Estado requirente pueda participar en lo siguiente:

- Ofrecer al representante del Estado requirente la oportunidad de hacer preguntas directamente o a través de la autoridad ejecutora a la persona física y que preste Declaración.

- Que al representante del Estado requirente les exhiban libros, documentos, registros u otros bienes muebles o documentos sobre bienes inmuebles.

- Permitir a la autoridad competente del Estado requiriente que someta preguntas por escrito sobre el objeto presentado, a los cuales deberá responder el individuo que presentó los libros, documentos, registros y otros bienes. 
El Acuerdo de Intercambio de Información suscrito por el Perú con AFIP también incluye fiscalización que contempla los siguientes aspectos:

- Objeto de la fiscalización simultánea

- Selección de casos y procedimientos de fiscalización

- Selección del sector y periodo a fiscalizar

- Adhesión a la fiscalización

- Interrupción de una Fiscalización simultanea.

El Convenio suscrito por el Perú con el Servicio de Rentas Internas - SRI de Ecuador no incluye fiscalización.

Estos acuerdos tienen límites en cuanto a que no es posible suministrar información que no se pueda obtener sobre la base de su propia legislación o práctica administrativa y no se puede obligar al otro Estado a adoptar medidas contrarias a sus normas internas.

\subsubsection{Acuerdos de Intercambio de Información con Organismos Internacionales}

El Perú en el año 2017, suscribió la Convención sobre Asistencia Administrativa Mutua en Materia Fiscal, incorporándose a la lista de países que han emprendido una política de transparencia fiscal internacional y de lucha contra la evasión y elusión fiscal.

El MEF en su página WEB señala lo siguiente

El Ministerio de Economía y Finanzas, en representación del Perú, suscribió el día de hoy la Convención sobre Asistencia Administrativa Mutua en Materia Tributaria, la cual le permitirá el intercambio de información financiera y tributaria con más de 100 países integrantes del Foro Global sobre Transparencia e Intercambio de Información de la OCDE.

Cabe destacar que la Convención permite, el intercambio de información financiera así como tributaria sobre ganancias de capital, intereses y regalías, entre otros, que los residentes peruanos tengan en el exterior, así como aquella que los residentes del exterior tengan en el Perú. Dicho intercambio puede ser automático, a solicitud o de manera espontánea. (MEF, 2017) 
La Convención sobre Asistencia Administrativa Mutua en Materia Fiscal suscrita entre el Perú y la OCDE fue Publicado en el diario El Peruano el 30/08/2018, en su primer artículo “Objeto y Ámbito Subjetivo de la Convención” estipula lo siguiente:

1) Sujeto a lo dispuesto por el Capítulo IV, las Partes se prestarán asistencia administrativa mutua en asuntos fiscales. Dicha asistencia puede incluir, de considerarlo apropiado, medidas adoptadas por órganos judiciales.

2) Dicha asistencia administrativa incluirá:

a. intercambio de información, incluyendo auditorías fiscales simultaneas y participación en auditorías en el extranjero;

b. asistencia en el cobro, incluyendo el establecimiento de medidas cautelares;

c. la notificación o traslado de documentos.

3) Las Partes proporcionarán asistencia administrativa, ya sea si la persona afectada es residente o nacional de una Parte o de cualquier otro Estado (Convención sobre Asistencia Administrativa Mutua en Materia Fiscal, 2018)

Esta Convención con la OCDE entró en vigencia el 01/09/2018 y como se podrá observar, incluye acuerdo de intercambio de información, auditorías fiscales simultaneas e incluso participación de auditorías en el extranjero.

Recientemente, el Perú ha firmado el Acuerdo Multilateral entre Autoridades Competentes para el Intercambio País por país (Multilateral Competent Authority Agreement on the Exchange of Country-by-Country Reports - CbC MCAA):

La Administración Nacional de Aduanas y Administración Tributaria - SUNAT, publicó en su página web el listado de países con los que el Perú ha firmado el Acuerdo Multilateral entre Autoridades Competentes para el intercambio país por país (Multilateral Competent Authority Agreement on the Exchange of Country-by-Country Reports - CbC MCAA), que es efectivo para periodos tributarios que comienzan en o después del 01 de enero de 2019.

Así, ahora el Perú mantiene activas sus relaciones de intercambio bilateral de información con 42 jurisdicciones (Deloitte )

El marco inclusivo de BEPS ha publicado información sobre los marcos legales nacionales para los informes de país por país (CbC Reporting) en todo el mundo. 
En el Perú, la implementación de este acuerdo se traduce en la implementación de normas como la obligación a presentar la Declaración Jurada Informativa de Precios de Transferencia - País por País, se encuentran obligados a presentarla los grupos y contribuyentes que tengan las siguientes condiciones:

Siempre que los ingresos devengados en el ejercicio gravable anterior al que corresponde la declaración, según los estados financieros consolidados que la matriz del grupo multinacional deba formular, sean mayores o iguales a dos mil setecientos millones y 00/100 soles (S/ 2700000 000,00), se encuentran obligados a presentar la declaración:

1) La matriz del grupo multinacional, domiciliada en el país.

2) El contribuyente domiciliado en el país que sea integrante del grupo multinacional cuando, no encontrándose la matriz domiciliada en el Perú, se verifique alguna de las siguientes situaciones:

a) Hubiera sido designado por el grupo como matriz representante.

b) Concurran alguna o varias de las condiciones contempladas en los numerales 1 al 3 del inciso del artículo $116^{\circ}$ del reglamento de la Ley del Impuesto a la Renta. (Superintendencia Nacional de Aduanas y Administración Tributaria, 2019)

Los Informes país por país (CbC Reporting) proporcionan a las Administraciones Tributarias información sobre los grupos de empresas multinacionales.

Esta información la podrán obtener en forma directa por la presentación de las declaraciones de los contribuyentes o a través de administraciones tributarias extranjeras, las cuales servirán de base para las fiscalizaciones e investigaciones futuras.

Estos informes País por País o Country by Country Reporting se implementan en aplicación de BEPS Acción 13 "El informe Documentación sobre precios de transferencia e informe país por país".

En el año 2017, la OCDE publicó un Manual de Implementación efectiva, el cual es un enfoque estandarizado para la documentación de precios de transferencia para las empresas multinacionales que consta de un archivo maestro, un archivo local y una obligación de que determinados grupos multinacionales presenten anualmente un informe país por país sobre las actividades globales y los atributos financieros del grupo por jurisdicción fiscal. 
El CbC Reporting es importante, pero el Manual indica que para su análisis hay que tomar en cuenta lo siguiente:

Demuestra que los informes país por país, utilizados junto con otra información y como base para futuras investigaciones pueden ser herramientas muy importantes para que las administraciones fiscales detecten e identifiquen los precios de transferencia y otros riesgos relacionados con BEPS. Por último, el Manual plantea advertencias acerca al riesgo de sacar conclusiones simplistas y engañosas si los informes país por país se utilizan aisladamente. (OCDE, 2017)

Según OCDE (2019) el Perú, a la fecha, tiene acceso a los Informes Pais por país (CbC Reporting) de los siguientes países:

\begin{tabular}{|l|l|l|l|l|}
\hline \multicolumn{3}{|c|}{ From jurisdiction: Peru } & To jurisdiction : & Legal Instrument \\
\hline Andorra $\left(^{*}\right)$ & France & Korea & Poland & CbC MCAA activated \\
Argentina & Germany & Latvia $\left(^{*}\right)$ & Portugal & CbC MCAA activated \\
Australia & Greece & Lithuania & San Marino $(+)$ & CbC MCAA activated \\
Belgium & Guernsey & Luxembourg & Singapore & CbC MCAA activated \\
Brazil & Hong Kong, China $(*)$ & Malaysia & Slovak Republic & CbC MCAA activated \\
Bulgaria & Iceland & Malta & Slovenia & CbC MCAA activated \\
Chile $\left({ }^{*}\right)$ & India & Mauritius $(*)$ & Switzerland & CbC MCAA activated \\
Colombia & Indonesia & Mexico & United Kingdom & CbC MCAA activated \\
Croatia $(*)$ & Ireland & Netherlands & Uruguay & CbC MCAA activated \\
Czech Republic & Italy & New Zealand & & CbC MCAA activated \\
Denmark & Japan & Norway & CbC MCAA activated \\
Estonia & Jersey & Pakistan & & CbC MCAA activated \\
\hline
\end{tabular}

(*) CbC MCAA activated - Effective for taxable periods starting on or after 01 January 2019 Fuente: Country-by-Country exchange relationships

(Country-by-Country exchange relationships, 2019)

Sin embargo, hay que reiterar que los CbC Reporting son muy útiles para las investigaciones y análisis fiscales, pero tienen que ser complementados con la documentación correspondiente para llegar a conclusiones más certeras. 


\subsection{Medidas Antielusivas contra Países o Territorios no cooperantes o de baja o nula imposición y Regímenes Fiscales preferenciales}

En la Ley de Impuesto a la Renta, a la fecha, se han legislado las siguientes normas antielusivas relacionadas con Países o Territorios no cooperantes o de baja o nula imposición y Regímenes Fiscales preferenciales:

a) Precios de Transferencia: Art. 32 y art. 32- A de la LIR y art. 108 al 119 del Reglamento

Los Precios de Transferencia se basan en el principio de Arm's Length y la normativa que se establece es para lograr que las empresas vinculadas determinen sus precios a valor de mercado como si se tratara de terceros independientes en similares condiciones con el objeto de evitar el traslado de beneficios a jurisdicciones de Nula o Baja tributación.

La nueva exigencia de las Declaraciones juradas informativas País por País es para facilitar el intercambio de información entre las administraciones tributarias para combatir la erosión de las Bases imponibles y la disminucion de la recaudación.

Otro cambio importante es que, tratándose de servicios prestados al contribuyente por sus partes vinculadas, dicho servicio deberá cumplir el test de beneficio; asimismo, la empresa debe presentar la documentación e información solicitada, como requisito necesario para la deducción del costo o gasto.

b) No Deducibilidad de Gastos y excepciones: Art 44 inc. m) de la LIR y Art. 54 de la LIR y Art. 119 del Reglamento

La prohibición de la deducción de los gastos y pérdidas de capital que provengan de operaciones que se realicen desde, hacia o a través de Países o Territorios no cooperantes o de Baja o Nula imposición y de Regímenes Fiscales Preferenciales es una medida utilizada, porque generalmente estas jurisidcciones no tienen transaparencia fiscal o no tienen intercambio de información con nuestro país; asimismo, se presume que los servicios no tienen sustancia económica. 
La norma hace excepciones en las siguientes operaciones: (i) crédito; (ii) seguros o reaseguros; (iii) cesión en uso de naves o aeronaves; (iv) transporte que se realice desde el país hacia el exterior y desde el exterior hacia el país; y, (v) derecho de pase por el canal de Panamá.

Sin embargo, la norma condiciona la deducción de dichas operaciones siempre que el precio o monto de la contraprestación sea igual al que hubiera pactado partes independientes en transacciones comparables.

Es importante señalar que en las adquisiciones de productos a estas jurisdicciones, el costo computable si es deducible.

c) No Compensación de Pérdidas de fuente extranjera: Art. 51

La Pérdida neta total de Fuente Extranjera no se compensa con la Renta de Fuente Peruana para la Determinación del Impuesto.

Los contribuyentes domiciliados en el país sumarán y compensarán entre sí los resultados que arrojen sus fuentes productoras de renta extranjera, y únicamente si de dichas operaciones resultara una renta neta, la misma se sumará a la renta neta del trabajo o a la renta neta empresarial de fuente peruana.

Sin embargo, en la compensación de los resultados que arrojen fuentes productoras de renta extranjera no se tomará en cuenta las pérdidas obtenidas por el contribuyente en países o territorios no cooperantes o de baja o nula imposición; o que provengan de operaciones o transacciones por las que obtengan o hubieran obtenido ingresos, rentas o ganancias sujetos a un régimen fiscal preferencial.

Es una medida utilizada por los mismos motivos que la prohibición de gastos y pérdidas de capital de estas jurisdicciones.

d) Transparencia Fiscal Internacional : Art. 114 al 116-A de la LIR y del art. 61al art 64D del Reglamento

El Régimen de Transparencia Fiscal Internacional es un mecanismo antielusivo que se encuentra vigente en Perú desde el ejercicio 2013, el cual se aplica a los contribuyentes domiciliados en el país que sean propietarios de entidades 
controladas no domiciliadas (ECND), constituidas o establecidas, o se consideren residentes o domiciliadas, en un país o territorio no cooperante o de baja o nula.

Del mismo modo, se debe cumplir la condición que estas rentas pasivas no estén sujetas al impuesto a la renta en dicha jurisdicción, o estándolo, el impuesto sea igual o inferior al setenta y cinco por ciento (75\%) del Impuesto a la Renta que correspondería en el Perú sobre las rentas de la misma naturaleza.

e) Venta Indirecta de Acciones: Art. 10 de la LIR y Art. 4-A y at. 39-G del Reglamento La Enajenación Indirecta de acciones grava las transferencias de acciones o participaciones representativas de personas jurídicas residentes en un país o territorio no cooperante o de baja o nula imposición, que a su vez tienen acciones o participaciones representativas de personas juridicas domiciliadas en el país porque se considera renta de fuente peruana.

La transferencia de acciones y participaciones de una persona jurídica domiciliada se encuentra gravada en el Perú.

Sin embargo, si no existiese la hipótesis de enajenación indirecta en la LIR para estos casos, la enajenación de las acciones o participaciones de la persona jurídica no domicilliada dueña de la persona jurídica peruana, no estaría gravada con el Impuesto a la Renta, lo cual facilitaría la elusión para el pago del impuesto correspondiente, por ese motivo se estableció esta norma antielusiva.

f) Gastos y Pérdidas de Instrumentos Financieros Derivados del artículo5-A, art. 44, inc, q), Art. 57

Los Instrumentos Financieros Derivados no considerados con fines de cobertura, son los celebrados con sujetos residentes o establecimientos permanentes situados en países o territorios no cooperantes o de baja o nula imposición; o con sujetos o establecimientos permanentes cuyas rentas, ingresos o ganancias provenientes de dichos contratos se encuentren sujetos a un régimen fiscal preferencial. 
El motivo es que en estas jurisdicciones existe la dificultad para las administraciones tributarias para obtemer informacion de dichas empresas por la falta de transparencia y acuerdos de intercambio de información.

g) Fondos de inversión, empresariales o no, las utilidades, rentas o ganancias de capital: Art. 14 -A de la LIR y Art. 5A del Reglamento

En el caso que los fideicomisos con retorno, se realicen desde, hacia o a través de países o territorios no cooperantes, cuando se produce la extinción del mismo y no se produzca el retorno de los bienes dado en fiducia, se efectuará el recalculo del Impuesto a la Renta en el periodo al que corresponda la transferencia fiduciaria, considerándolo como enajenación de los bienes o derechos.

Se busca evitar el diferimiento del pago del impuesto porque se parte del supuesto que es una enajenación definitiva. 


\section{CAPÍTULO III: MEDIDAS ADICIONALES QUE SE DEBEN IMPLEMENTAR EN EL IMPUESTO A LA RENTA}

\subsection{Incorporar en la Ley y el Reglamento del Impuesto a la Renta las siguientes}

modificaciones

a) Deducción de Gastos y Pérdidas de Capital provenientes de Países o Territorios no Cooperantes o de Baja o Nula Imposición o Régimen fiscal preferencial

Las Medidas Antielusivas no permiten la deducción de gastos y pérdidas de capital provenientes de operaciones que se realicen desde, hacia o a través de Países o Territorios no cooperantes o de Baja o nula imposición y de Regímenes Fiscales preferenciales.

Es una norma presuntiva que no admite prueba en contrario.

Sin embargo, el art. 44 inc. m) de la LIR hace sus excepciones porque señala explícitamente que no están incluidos los gastos derivados de las siguientes operaciones: (i) crédito; (ii) seguros o reaseguros; (iii) cesión en uso de naves o aeronaves; (iv) transporte que se realice desde el país hacia el exterior y desde el exterior hacia el país; y, (v) derecho de pase por el canal de Panamá. 
Asimismo condiciona su deducción, siempre que el precio o monto de la contraprestación sea igual al que hubiera pactado partes independientes en transacciones comparables.

Actualmente también se acepta como deducible los gastos vinculados a las adquisiciones de productos, porque son computables como parte del costo de dichos bienes, si bien no se enecuentra en la norma, está en el Informe $N^{\circ}$ 171-2007SUNAT/2B0000 que se pronuncia sobre este punto.

Estas excepciones, permiten afirmar que los demás gastos y pérdidas de capital deberían tener la posibilidad de la prueba en contrario.

El Perú no tiene Convenios de Doble Imposición o Acuerdos de Intercambio de Información con los países que están el Anexo No 1 Países o Territorios no cooperantes o de Baja o nula imposición. Asimismo, no tiene identificado en forma explícita los regímenes fiscales preferenciales lo cual limita los cruces de información y las fiscalizaciones a la Administración Tributaria.

Las prohibiciones a los gastos y pérdidas de capital perjudica a los contribuyentes en lo casos que las operaciones correspondan a transacciones reales.

Por lo tanto, la LIR debería ser modificada para que los gastos y pérdidas de capital que provienen de estas jurisdicciones se acepte la prueba en contrario, considerando las siguientes condiciones y requisitos:

- La carga de la prueba le corresponde al contribuyente, el cual debe acreditar con la documentación correspondiente que es una operación o transacción efectivamente realizada.

- La valorizacion de los gastos y operaciones que generaron la pérdida de capital sea de acuerdo a las normas de precios de transferencia y su test de beneficio.

- En el caso de los gastos y pérdidas de capital provenientes de jurisdicciones con regimen fiscal preferencial, que el contribuyente pueda acreditar cual es la tasa aplicada del Impuesto a la renta que paga en dicho país o territorio. 
- Que la Administración Tributaria a través de los convenios suscritos con la OCDE pueda obtener informacion de las empresas con quien se realice estas operaciones y validar la sustancia económica de las mismas. Esto, dependiendo del monto de la operacion y de los factores de calificación de los Países o Territorios no cooperantes o de Baja o nula Imposición o Regimen fiscal preferencial, mientras más riesgoso es, la exigencia de la probanza sera mayor.

b) No Compensación de Perdidas de fuente extranjera y No compensacion de Pérdidas de Países o Territorios no cooperantes o de Baja o nula Imposición o Regimen fiscal preferencial.

La Pérdida neta total de Fuente Extranjera no se compensa con la Renta de Fuente Peruana para la Determinación del Impuesto a la Renta.

Es así que, en la compensación de los resultados que arrojen fuentes productoras de renta extranjera, no se toma en cuenta las pérdidas obtenidas por el contribuyente en países o territorios no cooperantes o de baja o nula imposición; o que provengan de operaciones o transacciones por las que obtengan o hubieran obtenido ingresos, rentas o ganancias sujetos a un régimen fiscal preferencial.

Entonces, en el caso de las Pérdidas de Fuente Extranjera tenemos algunos aspectos a considerar:

b.1) La no Compensación de las Pérdidas de Fuente Extranjera contra la Renta de Fuente Nacional

En los países de Argentina, Bolivia, Colombia, Chile, Ecuador y Venezuela las pérdidas de fuente extranjera pueden compensarse con las rentas de fuente extranjera, si el resultado de dicha compensacion es Renta Neta se suma a la Renta Neta empresarial de fuente nacional, en caso contrario la pérdida neta de fuente extranjera no se puede compensar con la renta de fuente nacional, esta información lo señala Llaque Sanchez (2012):

Del estudio hemos podido establecer que todos los países cedularízan las rentas de fuente extranjera e impiden la compensación de las pérdidas que 
pudieran haberse obtenido en el extranjero con las utilidades de fuente nacional. Esta disposición busca proteger la recaudación de los países. (pág. 198)

Como se podrá observar, en el Perú la no compensación de la pérdida de fuente extranjera con la Renta de Fuente Nacional (Peruana) es una norma similar a los países mencionados. En el año 2016, en Argentina, la pérdida (quebranto) de fuente extranjera sigue prohibida de ser aplicada contra la renta de fuente Argentina.

b.2) La no compensación de la Pérdida de Fuente Extranjera contra la Renta Neta de Fuente Extranjera de ejercicios futuros.

Respecto a la Pérdida Tributaria de Fuente Extranjera, Porto Urrutia (2017) señala que no está claro en el artículo 51 de la LIR si dicha perdida puede ser arrastrada para ejercicios futuros:

Consideramos que el artículo 51 de la LIR se limita a señalar en el primer término que la pérdida neta de fuente extranjera no es computable, pasando luego a precisar que esto significa que la misma no es compensable a fin de determinar el impuesto. El párrafo analizado se limita a reiterar una sola idea, sin que se pronuncie de manera expresa sobre la posibilidad o imposibilidad que las pérdidas de fuente extranjera sean compensadas en ejercicios futuros contra otras rentas de fuente extranjera (pág. 309)

Sin embargo, la Administración Tributaria en su Informe No 074-2016 SUNAT/5D0000 establece su posición que "No corresponde arrastrar las pérdidas de fuente extranjera de ejercicios anteriores a fin de compensarlas contra futuras rentas netas de fuente extranjera" (Superintendencia Nacional de Aduanas y Administración Tributaria, 2016, pág. 6)

Por lo tanto, se debería modificar el artículo 51 de la LIR, precisando la prohibición de la Compensacion de pérdidas de fuente extranjera contra futuras rentas netas de fuente extranjera.

Sin embargo, en el Perú se podría proponer que las pérdidas de fuente extranjera se compensen con rentas de fuente extranjera del mismo país con el objeto 
de permitir el arrastre de dicha pérdida en la compensación de futuras rentas de fuente extranjera país por país.

En la legislación comparada, se observa que en Argentina sí se permite el Arrastre de pérdidas de fuente extranjera (Quebrantos de Fuente extranjera) en los 5 ejercicios siguientes al de su generación para ser compensadas contra las rentas netas de fuente extranjera, siempre y cuando las actividades que generaron dicho Quebranto no sean tipificadas en sus normas como renta de fuente Argentina:

Llama la atención el caso de Argentina, en éste país si se permite el arrastre de las pérdidas generadas en el exterior, las mismas que solo pueden ser compensadas contra las utilidades futuras de la misma fuente. (Llaque Sanchez, 2012)

Los quebrantos provenientes de actividades cuyos resultados se consideren de fuente extranjera, solo podrán compensarse con ganancias de esa misma fuente y se regirán por las disposiciones del artículo 134 de la LIG. (MR Consultores - Departamento de Capacitación, pág. 10)

b.3) La no compensación de las Pérdidas obtenidas en países o territorios no cooperantes o de baja o nula imposición; o un régimen fiscal preferencial de Fuente Extranjera.

De acuerdo al Artículo 51 de la LIR, en la compensación de los resultados que arrojen fuentes productoras de renta extranjera no se tomará en cuenta las pérdidas obtenidas por el contribuyente en países o territorios no cooperantes o de baja o nula imposición; o que provengan de operaciones o transacciones por las que obtengan o hubieran obtenido ingresos, rentas o ganancias sujetos a un régimen fiscal preferencial. (TUO Ley del Impuesto a la Renta - Decreto Supremo No 179-2004-EF y Modificatorias, 2018)

Es una medida utilizada por los mismos motivos que la prohibición de gastos de estas jurisdicciones: Ausencia de Transaprencia e Intercambio de Información.

En Argentina el articulo 135 de la Ley del Impuesto a las Ganancias establece que las sociedades por acciones constituidas en países o territorios de baja o nula imposición cuyas ganancias tengan un origen principalmente en intereses, 
dividendos, regalías, alquileres u otras ganancias pasivas similares, solamente podrán imputar los quebrantos de fuente extranjera provenientes de la enajenación de acciones, cuotas o participaciones sociales contra las utilidades netas de la misma fuente que provengan de igual tipo de operaciones.

Es decir, en Argentina, la compensación de las Pérdidas de Fuente extranjera en Territorios de Baja o Nula imposición es restringida por tipo de operación y que provengan de la misma fuente.

Rivera Manuel (2018) en relación a la Restricción de pérdidas provenientes de paraísos fiscales señala que en los casos de Portafolio de Inversion en el Exterior de una Persona Natural, se modifique la norma para que dichas pérdidas "Podrían ser computables contra las rentas netas generadas en el mismo territorio, mas no contra las rentas generadas en otros territorios" (pág. 4)

Entonces respecto a las Pérdidas de Fuente extranjera se sugiere estas modificaciones en la LIR y su reglamento, considerando las siguientes condiciones y requisitos:

- La Pérdida de Fuente Extranjera pueden ser arrastradas en los siguientes ejercicios compensadolas con las futuras Rentas Neta de Fuente extranjera del mismo País, es decir el control tiene que ser País por País, aplicando los mismos límites que el arrastre de pérdidas de fuente peruana.

- La carga de la prueba le corresponde al contribuyente, el cual debe acreditar dichas pérdidas de Fuente extranjera con las declaraciones, pagos, liquidaciones de Impuestos y documentos del país del cual proviene.

- Las Pérdidas provenientes de un País o Territorio no cooperante o de baja o nula imposición y de un Régimen fiscal preferencial pueden ser compensados con las Rentas Neta de la misma jurisdicción, es decir país por país, aplicando el arrastre de la pérdida para ejercicios futuros pero con el límite de 4 años.

- La carga de la prueba le corresponda al contribuyente, que deberá acreditar que dichas pérdidas de capital corresponden a transacciones reales. 
- Que la Administración Tributaria, a través de los convenios suscritos con la OCDE, pueda obtener información de las empresas que tienen dichas pérdidas y validarlas dependiendo del monto de la operación y de los factores de calificación de los Países o Territorios no cooperantes o Baja o nula Imposición o Régimen fiscal preferencial, mientras más riesgoso es, la exigencia de los requisitos sera mayor.

Si bien las medidas defensivas en las normas peruanas son válidas para hacer frente a la erosión de la Base Imponible y traslado de beneficios a dichas jurisdicciones, las restricciones a la deducción de gastos y pérdidas de capital, y compensación de pérdidas en la LIR y su reglamento se puede modificar para permitir la prueba en contrario, para que los contribuyentes que realicen transacciones reales no se vean perjudicados.

Esto deberá ser condicionado a que la Administración Tributaria pueda efectuar el cruce correspondiente en las jurisdicciones de donde provienen dichas operaciones, el cual deberá ser evaluado en función a los montos e importancia de las mismas.

En la actualidad, no tenemos convenios de Intercambio de Información suscritos con países o territorios no cooperantes o de Baja o nula Imposición o Régimen fiscal preferencial, pero mientras tanto debemos aprovechar al máximo los convenios suscritos con la OCDE para validar las operaciones que vienen de esas jurisdicciones.

\subsection{Suscribir más Acuerdos de Intercambio de Información}

A la fecha, solamente tenemos 7 Convenios de Doble Imposición y 3 acuerdos de intercambio de información, los cuales son muy pocos para evitar la doble imposición y combatir la erosión de las Bases Imponibles y Traslados de Beneficios.

En todos ellos existe el acuerdo de intercambio de Información por solicitud específica; sin embargo, el Intercambio de información Automática y Espontánea solo está estipulado en los acuerdos suscritos con los Estados Unidos de América, con la AFIP de Argentina y SRI de Ecuador. 
En el Acuerdo con la AFIP Argentina contempla la fiscalización simultánea, en el acuerdo con Estados Unidos no dice explícitamente la palabra fiscalización pero si permite la participación de representantes de la autoridad competente en las investigaciones y procedimientos administrativos de fiscalización y en Ecuador no se contempla dicha posibilidad.

Con Organismos internacionales, tenemos suscritos dos Acuerdos Multilaterales de la OCDE: a) La Convención sobre Asistencia Administrativa Mutua en Materia Fiscal (CAAMF) suscrita entre el Perú y la OCDE y b) el Acuerdo Multilateral entre Autoridades Competentes para el Intercambio País Por país (MCAA)

En el acuerdo CAAMMF de la OCDE que Perú ha suscrito, se permite el Intercambio de Información, auditorías fiscales simultaneas y auditorías fiscales en el extranjero; sin embargo, cada país que suscribió este acuerdo consignó en los mismos sus reservas y limitaciones.

En el acuerdo MAAC de la OCDE que nuestro país ha suscrito, se permite el intercambio de los informes país por país (CbC Reporting) que son declaraciones informativas presentadas por los precios de transferencia, que en el caso de Perú tiene acceso a esta información de 45 países señalados en párrafos anteriores.

Suscribir convenios de doble imposición lleva mucho tiempo y es complicado, por ese motivo es más accesible que el Perú suscriba más acuerdos de intercambio de Información, especialmente con los considerados países o territorios no cooperantes o de baja o nula imposición, o régimen fiscal preferencial.

Consideramos que el Acuerdo de Intercambio de Información suscrito por el Perú con Argentina es el modelo idóneo a ser utilizado para los futuros acuerdos porque contempla lo siguiente:

- Intercambio de información especifica,

- Intercambio de Información Automatica

- Intercambio de Información Espontanea

- Fiscalización Simultánea, selección del periodo a fiscalizar y de los procedimientos de fiscalización. 
Este modelo de Acuerdo de Intercambio de Información permitirá a la Administración Tributaria una mejor lucha contra la erosión de las Bases imponibles y el traslado de beneficios, solo cabría agregar las auditorias fiscales en el extranjero, que sí está estipulada en el Convenio CAAMMF suscrito con la OCDE.

Mientras tanto, se debe maximizar el uso de los dos acuerdos Multilaterales de la OCDE, en el caso del acuerdo MCCA CbC está implementado en la normativa peruana, en el caso del convenio CAAMMF el Código tributario ya fue modificado; sin embargo, se debería implementar procedimientos administrativos para poder usar estos convenios en materia de recaudación y fiscalización.

\subsection{Los Regímenes Fiscales Preferenciales deben ser publicados en forma explícita en las normas peruanas}

En la Ley del Impuesto a la Renta y su Reglamento están estipulados los factores para calificar a un País o Territorio que tiene un Régimen Fiscal Preferencial.

El artículo 86 del Reglamento establece como uno de los criterios para califiar un Régimen Fiscal preferencial que la tasa aplicable del impuesto a la renta sobre las rentas, ingresos o ganancias sujetas al régimen fiscal, de conformidad con el artículo 87, cualquiera fuese la denominación que se dé a este tributo, sea cero por ciento $(0 \%)$ o inferior al sesenta por ciento $(60 \%)$ de la que correspondería en el Perú sobre rentas de la misma naturaleza a sujetos domiciliados. (Reglamento del Impuesto a la Renta - Decreto Supremo No 122-94-EF y sus Modificatorias, 2018)

Asimismo, en el artículo 87 del Reglamento de la LIR indica cómo se debe calcular la Tasa aplicable.

Otro criterio para calificar jurisdicciones con Regímenes Fiscales preferenciales es que estos hayan sido calificados por la OCDE como regímenes perniciosos o potencialmente perniciosos por cumplir con el acápite (iii) del cuarto párrafo del inciso m) del artículo 44 de la Ley, aun cuando el país o territorio del régimen se encuentre en proceso de eliminarlos o modificarlos.

Sin embargo, no está publicada en la Ley o Reglamento del Impuesto a la renta, cuales son los países que tienen regímenes perniciosos o potencialmente perniciosos según la OCDE. 
El BEPS se originó con los casos emblemáticos que sucedieron en Irlanda que se describe a continuación:

Gigantes como Apple, Starbucks, Facebook, Microsoft, Yahoo! o Google, entre otros, se han aprovechado de una estrategia fiscal concedida por Irlanda que consiste en un acuerdo entre la Administración y el contribuyente. En el caso de la compañía fundada por Steve Jobs, ese pacto buscaba una clara evasión fiscal, según los criterios de la Comisión Europea.

Los 'tax rulings' permiten a las compañías trasladar flujos entre sus filiales en diferentes países en función de las ventajas fiscales que ofrecen determinadas naciones. La mayoría de las compañías que los han solicitado en Irlanda en la última década provienen de Estados Unidos o del Reino Unido. Pero esos acuerdos afectan a otros países, como las compañías belgas, holandesas, suizas o de Luxemburgo.

El pasado año han saltado a la luz 340 compañías que utilizaban tax rulings en Irlanda, Luxemburgo y Holanda, pero esa cifra apenas supone un número pequeño frente a las que todavía no han tomado estado público. (La Información, 2016)

Irlanda, además de regímenes fiscales preferenciales, tiene una tasa nominal $12.5 \%$ que incluso ha sido reducida para compañías tecnológicas según esta noticia:

Después, crea otra empresa y establece su sede en Irlanda, donde el Impuesto de Sociedades es el más bajo de la UE con un 12,5\% en el tipo general, aunque ahora acaba de rebajarlo al 6,25\% para las compañías tecnológicas (en realidad para aquellos beneficios derivados de la propiedad intelectual como las patentes) (Diario de Navarra, 2016)

Por lo expuesto, sugerimos que los Regímenes Fiscales preferenciales que hayan sido calificados por la OCDE como regímenes perniciosos o potencialmente perniciosos sean publicados en forma explicita en las normas peruanas.

También sugerimos que los países o territorios que tienen una tasa nominal inferior al Impuesto a la Renta sea publicado en la WEB de la Administracion Tributaria como referencia para que los contribuyentes evalúen que países con los que tienen operaciones podrían ser contingentes, sería una buena alerta para tomar en cuenta. 


\subsection{Modificación en la Tasa de Retención del Impuesto a la Renta: Intereses}

En el caso de las personas naturales y sucesiones indivisas no domiciliadas en el país, están sujetas al Impuesto por sus rentas de Fuente Peruana cuando los intereses les pague o acredite un generador de rentas de tercera categoría, la tasa es de $4.99 \%$ excepto:

- Si hay vinculación entre las partes la tasa de retención es 30\%

- Cuando los intereses deriven de operaciones realizadas desde o a través de países o territorios no cooperantes o de baja o nula imposición, o con sujetos que obtengan rentas ingresos o ganancias o sujetos a un régimen fiscal preferencial por dichas operaciones la tasa de retención es 30\% (art.54 de la LIR)

Sin embargo, en el caso de las personas jurídicas no domiciliadass cuando el sujeto domiciliado en el Perú les paga los intereses les aplican las siguientes tasas de interés:

- Intereses provenientes de créditos externos $4.99 \%$ siempre que cumpla los requisitos que señala la norma (Art 56 inc.a) de la LIR).

- Intereses que abonan al exterior las empresas de operaciones multiples establecidas en el Perú a que se refiere el literal A del artículo 16 de la Ley num. 26702, Ley General del Sistema Financiero y del Sistema de Seguros y Orgánica de la Superintendeencia de Banca y Segruos como resultado de la utilización en el país de sus líneas de crédito en el exterior : 4.99\% (Art. 56 inc. b) de la LIR)

- Intereses derivados de créditos externos que no cumplan con el requisito establecido en el numeral 1) del inc a) o en la parte que excedan de la tasa máxima establecida en el numeral 2 del mismo inciso, los intereses que abonen al exterior las empresas privadas del país por créditos concedidos por una empresa del exterior con la cual se encuentra vinculada, o los intereses que abonen al exterior las empresas privadas del país por créditos concedidos por un acreedor cuya intervención tiene como propósito encubrir una operación de crédito entre partes vinculadas: treinta por ciento (30\%) (Art. 56 inc. j) de la LIR) 
El artículo 30 del Reglamento de la LIR hace una excepción, porque para efecto de los intereses a que se refiere el inciso j) del artículo $56^{\circ}$ de la Ley, no se consideran partes vinculadas las empresas privadas del país con la empresa del exterior si cumplen las condiciones estipuladas en dicho artículo.

Como se podrá observar, a las personas jurídicas no domiciliadas no se les incrementa la tasa de retención por los intereses que deriven de operaciones realizadas desde o a través de países o territorios no cooperantes o de baja o nula imposición, o con sujetos que obtengan rentas ingresos o ganacias o sujetos a un régimen fiscal preferencial.

Esta distinción de tratamiento no es equitativa, por lo tanto, a las personas jurídicas no domiciliadas también se les debe retener el $30 \%$ cuando las operaciones deriven de estas jurisdicciones de baja o nula imposición o con regímenes preferenciales.

\subsection{CONCLUSIONES Y RECOMENDACIONES}

- El Perú, con las modificaciones a la Ley y Reglamento del Impuesto a la Renta que se ha realizado en el año 2018 está en camino de la estandarización de las normas tributarias peruanas de acuerdo a las recomendaciones de la OCDE y se ha adherido al Marco Inclusivo de BEPS con el objetivo de combatir la erosión de las Bases Imponibles y el Traslado de Beneficios.

- La normativa está vigente a partir del 2019; sin embargo, dentro de estas medidas defensivas siguen las prohibiciones de deducción en el Impuesto a la Renta de gastos y pérdidas de capital provenientes de países o territorios no cooperantes o de baja o nula imposición y Regímenes fiscales preferenciales, lo cual perjudica al contribuyente en el caso de transacciones reales.

- Permanece la prohibición del Arrastre de Pérdidas de Fuente Extranjera; asimismo, en la compensación de los resultados que arrojen fuentes productoras de renta extranjera no se toma en cuenta las pérdidas obtenidas por el contribuyente en países o territorios no cooperantes o de baja o nula imposición; o que provengan de operaciones o transacciones de un régimen fiscal preferencial. 
- En el Reglamento de la la LIR, uno de los criterios para calificar un Régimen fiscal preferencial es que la jurisdiccón haya sido calificada por la OCDE como régimen pernicioso o potencialmente pernicioso; no obstante, la norma peruana no publica qué países o territorios son los identificados con dichos regímenes.

- El Perú solamente tiene 7 Convenios de Doble Imposición y 3 Acuerdos de Intercambio de información, los cuales son muy pocos para evitar la doble imposición y combatir la erosión de las Bases Imponibles y el Trasaldo de Beneficios, además que los intercambios de información plasmados en dichos CDIs y acuerdos suscritos no son uniformes, cada uno de ellos tienen diferentes alcances y limitaciones. En el acuerdo con AFIP, Argentina se permite la fiscalización simultánea, el AAIT con USA se permite participar a un representante de la autoridad competente del Estado requirente en procedimientos de delito y fiscalización, y en el Convenio con SRI del Ecuador no existe dicha posibilidad.

- Recientemente, el Perú ha suscrito el CAAMMF de la OCDE para lo cual ya se modificó el Codigo Tributario para poder realizar las actuaciones y procedimientos para prestar y solicitar asistencia administrativa mutua en materia tributaria, así como para el control de las obligaciones formales vinculadas con la citada asistencia administrativa mutua, pero todavía falta normar los procedimientos administrativos especificos para realizar la acciones de dichos acuerdos, tales como la auditoría simultánea y auditoría en el extranjero. De esta forma serán útiles en los procedimientos de recaudación y fiscalización.

- En el caso del Acuerdo MCCA de la OCDE se puede intercambiar la información del Informe país por país (declaracion jurada informativa de precios de transferencia) con 45 países. Ya está implementado, sin embargo, dicho CbC Reporting que debe servir para un primer análisis, luego deberá ser complementado con información adicional para llegar a mejores conclusiones.

- En el caso de la tasa de Retención del Impuesto a la renta por el pago de intereses por Créditos obtenidos en países o territorios no cooperantes de Baja o nula imposicion o en Regímenes preferenciales, la norma hace una distinción entre personas naturales y personas jurídicas, porque a las primeras le aplican una tasa de 
retención del 30\%, sin embargo a las empresas le aplican una tasa de retención de $4.99 \%$, lo cual no es equitativo.

Por lo expuesto, se plantean las siguientes recomendaciones:

- En la Ley y Reglamento del Impuesto a la Renta se debe permitir que los gastos y pérdidas de capital provenientes de países o territorios no cooperantes o de baja o nula imposición o de un régimen fiscal preferencial, puedan ser deducibles, pero trasladando la carga de la prueba al contribuyente, ademas del cumplimiento de una serie condiciones señaladas en el punto 3.1 literal a) del presente trabajo de investigación.

- Las Autoridades competentes deben precisar en el articulo 51 de la LIR la prohibición de la Compensacion de pérdidas de fuente extranjera contra futuras rentas netas de fuente extranjera, porque ese es el objeto de la norma tal como lo evidencia el Informe emitido por la Administración Tributaria.

- Sin embargo, sugerimos que se debe permitir que la Pérdida de Fuente Extranjera pueda ser arrastrada en los siguientes ejercicios compensándola con la futura Renta Neta de Fuente extranjera del mismo País; es decir, el control tiene que ser País por País, aplicando los mismos límites que el arrastre de pérdidas de fuente peruana, trasladando la carga de la prueba al contribuyente y cumpliendo otras condiciones señaladas en el punto 3.1 literal b) del presente trabajo de investigación.

- En la compensación de los resultados que arrojen fuentes productoras de renta extranjera (Rentas y Perdidas) se debe permitir que se compensen las pérdidas obtenidas por el contribuyente en países o territorios no cooperantes o de baja o nula imposición; o que provengan de operaciones o transacciones sujetos a un régimen fiscal preferencial, con la Renta Neta de la misma jurisdicción, es decir país por país, territorio por territorio aplicando el arrastre de la perdida para ejercicios futuros pero con el límite de 4 años, asimismo se traslada la carga de la prueba al contribuyente y se establece condiciones indicadas en el punto 3.1 literal b) del presente trabajo de investigación.

- El Perú debe suscribir más acuerdos de intercambio de información con los países o territorios no cooperantes de baja o nula imposición o que tienen regímenes 
preferenciales, priorizando las jurisdicciones con los cuales las personas juridicas y personas naturales tienen mas operaciones.

- El modelo de Acuerdo de Intercambio de Información suscrito por el Perú con la Argentina es el modelo más idóneo a ser utilizado para los futuros acuerdos de intercambio de información porque contempla lo descrito en el punto 3.2 del presente trabajo de investigacion, debiendo incluir la posibilidad de auditorias fiscales en el exterior como lo estipula el CAAMMF suscrito con la OCDE.

- Utilizar al máximo los convenios Multilaterales de la OCDE suscritos por el Perú: a) CAAMMF y b) MCAA CbC para cruzar y validar las operaciones realizadas por las empresas domiciliadas en el Perú desde, hacia o a través de los países o territorios no cooperantes de baja o nula imposición y Regímenes Fiscales preferenciales, normando los procedimientos administrativos y protocolos que permitan la ejecución de los acuerdos de intercambio de información, de auditoría simultánea y auditoría en el extranjero, de tal forma que sean útiles en los procedimientos de recaudación y fiscalización.

- Los Regímenes Fiscales preferenciales que hayan sido calificados por la OCDE como regímenes perniciosos o potencialmente perniciosos deben ser publicados en forma explícita en las normas peruanas por las razones expuestas en el punto 3.3 del presente trabajo de investigación.

- La Tasa de Retención a las personas jurídicas no domiciliadas por los pagos de intereses que deriven de operaciones realizadas desde o a través de países o territorios no cooperantes o de baja o nula imposición, o con sujetos a un régimen fiscal preferencial, debe ser $30 \%$. 


\section{BIBLIOGRAFIA BÁSICA}

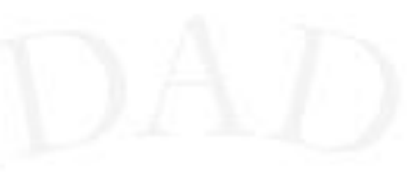

Alva Matteucci, M. (2001). Los Paraísos Fiscales. Analisis Tributario. Obtenido de http://blog.pucp.edu.pe/blog/blogdemarioalva/2009/04/17/los-paraisos-fiscales/

Bedoya Martinez, O., \& Rua, W. (2016). El concepto de evasión y elusión en términos de la Corte Constitucional, el Concejo de Estado y la Administración de Impuestos y Aduanas Nacionales. Obtenido de http://bibliotecadigital.udea.edu.co/bitstream/10495/8841/1/BedoyaOmar_2016 _ConceptoEvasionElusion.pdf

Bravo Cucci, J. (2006). La Elusión, el Fraude a la Ley Tributaria y el Segundo párrafo de la Norma VIII del Titulo Preliminar del Codigo Tributarui. IPDT Revista 44. Obtenido de http://www.ipdt.org/uploads/docs/04_Rev44_JBC.pdf

Centro Interamericano de Administraciones Tributarias - CIAT. (2009). Fortalecimiento de la Capacidad de la Administración Tributaria. Conferencia Tecnica del CIAT Caso Práctico 2.1 El Intercambio de Información y la Asistencia Administrativa para el Cobro como Mecanismos Efectivos de Control al Fraude, La Evasión y la Elusión. Napoles Italia. Obtenido de https://www.ciat.org/Biblioteca/ConferenciasTecnicas/2009/Espanol/italia_2009 _tema2.1_sanchez_argentina.pdf

Chavez Chavez, J. L. (2014). Los paraisos fiscales y su impacto global en America Latina. CIMEXUS Revista Nicolaita de Politicas Publicas. Obtenido de https://cimexus.umich.mx/index.php/cim1/article/view/190/159

Comisión Europea - Comunicado de prensa. (diciembre de 2017). Equidad tributaria: la UE publica la lista de países y territorios no cooperadores en materia fiscal. Obtenido de European Commission Press Release Data Base: http://europa.eu/rapid/press-release_IP-17-5121_es.htm

Deloitte . (s.f.). Publican listado de países con los cuáles Perú firmó el Acuerdo Multilateral entre Autoridades Competentes para el intercambio de información País por País. Obtenido de https://www2.deloitte.com/pe/es/pages/tax/articles/Peru-firma-acuerdomultilateral-entre-autoridades-competentes.html

Diario de Navarra. (2016). El 'doble irlandés' y el 'sándwich holandés', las vías de las tecnológicas para eludir impuestos, La OCDE se ha puesto en marcha el 
denominado programa BEPS de lucha contra la erosión de bases imponibles. Obtenido de

https://www.diariodenavarra.es/noticias/negocios/economia/2016/07/02/las_vias _las_tecnologicas_para_eludir_impuestos_468742_1033.html

Direccion General de Politicas Ingresos Publico, MEF. (2018). Exposicion de Motivos de Proyecto de Decreto Legislativo que Modifica la Ley del Impuesto a la Renta. Lima, Peru.

Dirección General de Políticas Ingresos Publico, MEF. (2018). Proyecto de Decreto Supremo que Modifica el Reglamento de La Ley del Impuesto a La Renta. Lima.

El Congreso de Colombia. (2018). Estatuto Tributario Nacional. Colombia. Obtenido de https://estatuto.co/?o=24

El Economista (México). (mayo de 2018). OCDE detecta 175 regímenes fiscales preferenciales: Barbados, Chile y Uruguay los tienen en A. Latina. América Economia. Obtenido de https://www.americaeconomia.com/economiamercados/finanzas/ocde-detecta-175-regimenes-fiscales-preferencialesbarbados-chile-y

El Peruano. (2018). Convención sobre Asistencia Administrativa Mutua en Materia Fiscal.

Falcon y Tella, R., \& Pulido Guerra, E. (2010). Derecho fiscal internacional. Madrid, España: Marcial Pons; ediciones Jurídicas y Sociales. Obtenido de https://app.vlex.com/\#WW/sources/14706

Garcia Novoa, C. (2008). Cláusula general anti-elusiva y la norma VIII peruana*. THEMIS: Revista de Derecho,. Obtenido de https://dialnet.unirioja.es/servlet/articulo?codigo=5110529

General Secretariat of the Council, E. (2017). Council Conclusion on the EU list of noncooperative jurisdictions for tax purposes. Bruselas, Union Europea. Obtenido de https://www.consilium.europa.eu/media/31945/st15429en17.pdf

Gutierrez de Pablo, G. (2015). Análisis Jurídico de los Paraísos Fiscales y Medidas para Evitar sus Efectos. Malaga, España. Obtenido de https://riuma.uma.es/xmlui/bitstream/handle/10630/12862/TD_GUTIERREZ_D E_PABLO_Gonzalo.pdf?sequence $=1$

IPDT. (2019). La Clausula Antielusiva General en el Ordenamiento Peruano. XIV Jornadas Nacionales de Derecho Tributario. Perú.

Jimenez Macias, I. ((2017). El intercambio de información y el sistema fiscal internacional después de FATCA: diagnóstico y perspectivas. Madrid, España. Obtenido de https://eprints.ucm.es/43588/1/T39005.pdf

La Información. (2016). Irlanda, el paraíso fiscal que Google y otros colosos tecnológicos abandonarían. Obtenido de La Información: https://www.lainformacion.com/economia-negocios-yfinanzas/economia/irlanda-google-tecnologicos-podriantraicionar_0_952405381.html

Lalanne, G. (2006). Economia de Opcion y Fraude de Ley en el Derecho Tributario. IPDT - Revista 44 . Obtenido de http://www.ipdt.org/uploads/docs/03_Rev44_GAL.pdf

Llaque Sanchez, F. (2012). Efectos Financieros del Tratamiento de las Pérdidas Tributarias Compensables y su Influencia en las Decisiones de Inversión en la Región Andina. Obtenido de http://www.repositorioacademico.usmp.edu.pe/bitstream/usmp/585/3/llaque_fr. pdf 
Marieges , A., Suñer, J., Vallès, X., \& Vidal, P. (2012). Paraisos Fiscales Indices de Optimización Fiscal. Barcelona, España. Obtenido de https://www.bsm.upf.edu/documents/TESINA-PARAISOS-FISCALES.pdf

Marulanda Otálvaro, H., \& Heredia Rodríguez, L. (2016). Paraísos fiscales: una línea de contradicción entre la formalidad y la materialidad. Obtenido de http://www.ief.es/docs/destacados/publicaciones/documentos_trabajo/2015_15. pdf

MEF. (2012). Decreto Supremo N. ${ }^{\circ}$ 258-2012-EF.

MEF. (2017). Perú y OCDE firman convenio de intercambio de información tributaria y financiera con más de 100 países. Obtenido de https://www.mef.gob.pe/es/noticias/notas-de-prensa-y-comunicados?id=5532

MEF. (2018). Decreto Supremo No 340-2018-EF. Lima, Perú.

MEF. (2018). Reglamento del Impuesto a la Renta - Decreto Supremo No 122-94-EF y sus Modificatorias. Lima, Perú.

MEF. (2018). TUO Ley del Impuesto a la Renta - Decreto Supremo No 179-2004-EF y Modificatorias.

MR Consultores - Departamento de Capacitación. (s.f.). Teoria y Tecnica Impositiva 1 : Quebrantos. Obtenido de http://www.mrconsultores.com.ar/archivos/UnivBelgrano/Material_de_Aplicaci on/03\%20-\%20Quebrantos.pdf

OCDE. (1998). Harmful Tax Competition An Emerging Global Issue. Obtenido de http://www.oecd.org/tax/transparency/44430243.pdf

OCDE. (2013). Lucha contra la erosión de la base imponible y el traslado de beneficios. Obtenido de https://read.oecd-ilibrary.org/taxation/abordando-laerosion-de-la-base-imponible-y-la-deslocalizacion-debeneficios_9789264201224-es\#page1

OCDE. (2016). Combatir las prácticas fiscales perniciosas, teniendo en cuenta la transparencia y la sustancia, Acción 5 - Informe final 2015 Proyecto de la OCDE y del G-20 sobre la Erosión de la Base Imponible y el Traslado de Beneficiosv. Obtenido de https://read.oecd-ilibrary.org/taxation/combatir-laspracticas-fiscales-perniciosas-teniendo-en-cuenta-la-transparencia-y-lasustancia-accione-5-informe-finale-2015_9789264267107-es\#page43

OCDE. (2017). BEPS Acción 13 Informe país por país, Manual para la Implementación Efectiva. Obtenido de http://orientacion.sunat.gob.pe/images/imagenes/contenido/PreciosDeTransferen cia/informes-pais-por-pais-manual-para-la-implementacion-efectiva.pdf

OCDE/G20. (2015). Proyecto OCDE/G20 sobre la Erosión de la Base Imponible y el Traslado de Beneficios; Resúmenes Informes Finales 2015. Obtenido de https://www.oecd.org/ctp/beps-resumenes-informes-finales-2015.pdf

OECD. (2019). OECD. Obtenido de List of Unco-operative Tax Havens: http://www.oecd.org/ctp/harmful/list-of-unco-operative-tax-havens.htm

OECD Home. (2019). Country-by-Country exchange relationships. Obtenido de https://www.oecd.org/tax/beps/country-by-country-exchange-relationships.htm

OECD Home. (2019). Glossary of Tax Term. Obtenido de https://www.oecd.org/ctp/glossaryoftaxterms.htm\#R

OECD, Centre for Tax Policy and Administration;. (2009). Countering Offshore Tax Evasion Some Questions and Answers. OECD. Obtenido de http://www.oecd.org/ctp/exchange-of-tax-information/42469606.pdf

OECD.ORG. (2019). OECD. Obtenido de 10 Preguntas sobre BEPS: https://www.oecd.org/ctp/10-preguntas-sobre-beps.pdf 
OECD/G20 . (2015). Countering Harmful Tax Practices More Effectively, Taking into Account Transparency and Substance, Action 5 - 2015 Final Report. Obtenido de Countering Harmful Tax Practices More Effectively, Taking into Account Transparency and Substance, Action 5 - 2015 Final Report

OXFAM. (2016). Guerras Fiscales La carrera a la baja en la fiscalidad empresarial. INFORME DE POLÍTICAS DE OXFAM - RESUMEN. Obtenido de https://www.oxfamintermon.org/sites/default/files/documentos/files/Informe\%2 0Guerras\%20Fiscales\%20-\%20Resumen\%20Espa\%C3\%B1ol.pdf

Parlamento Europeo. (08 de 07 de 2015). La elusión fiscal y la evasión fiscal como obstáculos en los países en desarrollo. Resolución del Parlamento Europeo. Union Europea.

Picón Gonzales, J. L. (2016). Los paraísos fiscales como herramienta de planificación tributaria. Sevilla, España. Obtenido de https://idus.us.es/xmlui/handle/11441/39141

Porto Urrutia, J. (2017). Una Revisión al Régimen de Arrastre de Pérdidas de Fuente Extranjera por Parte de Personas jurídicas domiciliadas, Beneficio Tributario o una Restricción al derecho de los Contribuyentes? Obtenido de http://www.ipdt.org/uploads/docs/11_Rev62_JPPU.pdf

PRODECON. (2018). PRODECON - Procuraduria de la Defensa del Contribuyente. Boletin de Noticias Internacionales del 21 al 25 de Mayo 2018. Obtenido de https://www.prodecon.gob.mx/Documentos/boletinesinternacionales/2018/mayo/boletin_de_noticias_fiscales_internacionales_del_21 _al_25_de_mayo_de_2018_.pdf

Ramos Angeles, J. (2015). El Proyecto BEPS de la OCDE y el Mito del Fin de la Planificación Fiscal Internacional: Un Enfoque Crítico a Propósito de los Final Reports 2015. Revista Derecho \& Sociedad, $N^{\circ} 45$. Obtenido de http://revistas.pucp.edu.pe/index.php/derechoysociedad/article/download/15255/ 15723.

Rendon Lopez, A. (2014). Paraisos Fiscales y Oficinas Off Shore, Operaciones Ilicitas O Planificación Fiscal? Revista de la Facultad de Derecho de Mexico - UNAM. Obtenido de https://revistas-colaboracion.juridicas.unam.mx/index.php/revfacultad-derecho-mx/article/download/31361/28348

Rivera, M. (2018). Restricción de Pérdidas provenientes de Paraísos Fiscales. Obtenido de Asociacion Fiscal Internacional - Grupo Peruano: http://www.ifaperu.org/uploads/files/Rivera_05-06-2018.pdf

Schomberger Tibocha, J., \& López Murcia, J. (2007). La Problematica Actual de los Paraísos Fiscales. International Law: Revista Colombiana de Derecho Internacional. Obtenido de http://www.redalyc.org/articulo.oa?id=82401010

Superintendencia Nacional de Aduanas y Administración Tributaria. (2016). Informe No 074-2016-SUNAT/5D000. Obtenido de http://www.sunat.gob.pe/legislacion/oficios/2016/informe-oficios/i074-2016.pdf

Superintendencia Nacional de Aduanas y Administración Tributaria. (2019). Declaración Jurada Informativa País por País. Obtenido de http://orientacion.sunat.gob.pe/index.php/empresas-menu/impuesto-a-la-rentaempresas/fiscalidad-internacional-empresas/precios-de-transferenciaobligaciones-formales/7121-04-declaracion-jurada-informativa-pais-por-pais

Villagra Cayamana, R. A. (s.f.). Los Convenios para evitar la Doble Imposición y Prevenir la Evasion Fiscal. Obtenido de IFA: http://www.ifaperu.org/uploads/articles/316_01_manual_cdi.pdf 
Villanueva, W. (2017). Planificación Fiscal Agresiva, el nuevo paradigma de los precios de transferencia y la elusión en el Código Tributario. IUS Et Veritas $P U C P$. Obtenido de http://revistas.pucp.edu.pe/index.php/iusetveritas/article/view/19082/19287 